\title{
Transcriptional Regulation in Non-Alcoholic Fatty Liver Disease
}

\author{
Sandra Steensels ${ }^{\dagger}$, Jixuan Qiao ${ }^{\dagger}$ and Baran A. Ersoy *(D) \\ Joan \& Sanford I. Weill Department of Medicine, Weill Cornell Medical College, New York, NY 10021, USA; \\ sas2906@med.cornell.edu (S.S.); jiq2001@med.cornell.edu (J.Q.) \\ * Correspondence: bersoy@med.cornell.edu \\ t These authors have contributed equally to this work.
}

Received: 30 May 2020; Accepted: 2 July 2020; Published: 9 July 2020

\begin{abstract}
Obesity is the primary risk factor for the pathogenesis of non-alcoholic fatty liver disease (NAFLD), the worldwide prevalence of which continues to increase dramatically. The liver plays a pivotal role in the maintenance of whole-body lipid and glucose homeostasis. This is mainly mediated by the transcriptional activation of hepatic pathways that promote glucose and lipid production or utilization in response to the nutritional state of the body. However, in the setting of chronic excessive nutrition, the dysregulation of hepatic transcriptional machinery promotes lipid accumulation, inflammation, metabolic stress, and fibrosis, which culminate in NAFLD. In this review, we provide our current understanding of the transcription factors that have been linked to the pathogenesis and progression of NAFLD. Using publicly available transcriptomic data, we outline the altered activity of transcription factors among humans with NAFLD. By expanding this analysis to common experimental mouse models of NAFLD, we outline the relevance of mouse models to the human pathophysiology at the transcriptional level.
\end{abstract}

Keywords: non-alcoholic fatty liver disease; non-alcoholic steatohepatitis; transcription factors; inflammation; metabolic stress; fibrosis; lipid homeostasis; glucose homeostasis

\section{Introduction}

Obesity often results in the dysregulation of lipid and glucose metabolism and is therefore the primary risk factor for the pathogenesis of metabolic disorders, including cardiovascular disease, type 2 diabetes mellitus (T2DM), and non-alcoholic fatty liver disease (NAFLD) [1]. The global prevalence of NAFLD, which was $15 \%$ in 2005 , has quickly escalated to $24 \%$ by 2016 in a parallel trend to obesity [2]. NAFLD encompasses a spectrum of pathologies ranging from hepatocellular lipid accumulation (steatosis) to non-alcoholic steatohepatitis (NASH) characterized by steatosis and inflammation. In addition, chronic inflammation activates hepatic stellate cells (HSC), which promote fibrosis by secreting type I and III collagen and fibronectin into the extracellular matrix (ECM) [3]. When fibrotic NASH remains untreated, it can lead to cirrhosis and hepatocellular carcinoma (HCC) [4]. Despite alarming increases in prevalence, the treatment strategy of NAFLD remains limited to weight loss regiments and requires a more complete understanding of diet-induced pathogenesis of NAFLD in obese patients [5]. 
The pathogenesis of NAFLD is complex, and evolving theories have culminated in a two-hit versus multiple-hit hypotheses [6]. In the 'two-hit hypothesis', the first hit originates from the accumulation of more than $5 \%$ hepatic steatosis, during which insulin resistance emerges as a pathogenic contributor. This makes the liver more susceptible to a second hit, including oxidative stress, the production of pro-inflammatory cytokines, and apoptosis, which progress the disease to the necro-inflammatory stage defined as NASH [7]. In contrast, the 'multiple-hit' hypothesis encompasses the interplay of multiple factors whereby genetics, environment, unhealthy dietary habits, insulin resistance, adipocyte differentiation, and the intestinal microbiota together contribute to disease development and progression [8]. Regardless of the source of the hit (s), hepatic responses to extrahepatic stimuli are controlled by well-described transcriptionally regulated pathways that help transcribe the relevant biological machinery to maintain energy homeostasis. However, obesity-induced maladaptive activation or the inhibition of these transcriptional regulators often exacerbates lipid accumulation, insulin resistance, inflammation, and fibrosis [9].

The efforts toward identifying the promoters of obesity-induced NAFLD have relied heavily on rodent models due to limited access to and the variability within human samples arising from differences in disease stage, age, sex, medication, body weight, and other lifestyle choices such as alcohol consumption. However, rodent models do not capture all the features of the human pathophysiology. The rodent NAFLD models described in this review are categorized by their mode of induction using diet, chemicals, or genetic alteration (Box 1). For the diet-induced models, we highlight high-fat diet (HFD), Western diet (WD), methionine- and choline-deficient diet (MCD), choline-deficient L-amino acid-defined (CDAA) diet, and fructose-palmitate-cholesterol and trans-fat (FPC or NASH) diet. The chemically induced models include the combination of HFD with streptozotocin (STZ) supplementation or the use of carbon tetrachloride $\left(\mathrm{CCl}_{4}\right)$. For genetic models, we highlight the APOE2 knock-in (APOE2-KI) mouse [10], hepatocyte-specific phosphatase and tensin homolog (PTEN) knockout model [11], and Mice expressing urokinase-type plasminogen activator (uPA) under the control of the major urinary protein (MUP) promoter (MUP-uPA mice) [12].

In this review, we discuss our current understanding of the transcription factors that have been linked to the pathogenesis and progression of NAFLD. Transcription factors that are associated with obesity-induced liver injury and the pathogenesis and progression of NAFLD often serve essential biological functions in the maintenance of energy homeostasis and stress response. Furthermore, recent studies have indicated that the gut microbiota may contribute to NAFLD by altering the production of endogenous substrates that control the activity of hepatic transcription factors. Therefore, we have categorized these transcriptional regulators under lipid and glucose metabolism, inflammation, metabolic stress, fibrosis, and microbiome dysbiosis. Key transcriptional regulators that play significant roles in multiple metabolic responses have been addressed in all relevant categories. 
Box 1. Mouse models of non-alcoholic fatty liver disease (NAFLD).

Diet-based models

High-fat diet (HFD, $60 \mathrm{kcal} \%$ fat) and Western diet (WD, 40\% kcal fat and 40\% kcal carbohydrates)—HFD feeding of mice (8-12 weeks) leads to a phenotype similar to simple steatosis in humans, which is characterized by obesity, insulin resistance, and hyperlipidemia [13]. Alanine aminotransferase (ALT) and aspartate aminotransferase (AST) levels also become exacerbated after extended exposure ( $>8$ months). However, this diet barely induces fibrosis even after extended exposure (up to 1 year) [13].

$M C D$ diet-In the MCD diet, the absence of methionine (4-8 weeks) leads to hepatic injury, inflammation, and fibrosis, while the deficiency of choline leads to macrovesicular steatosis. Due to the nature of its pathogenesis, this model is less representative of the initiation of NAFLD in humans. Nonetheless, the diet induces progressive steatohepatitis leading to fibrosis, which is histologically similar to the human disease. The main drawback of MCD is its induction of body weight loss and decrease in plasma triglyceride levels [14].

CDAA diet-CDAA is similar to MCD due to their shared deficiency in choline. However, in CDAA, proteins are substituted with an equivalent and corresponding mixture of L-amino acids [15]. Animals fed CDAA develop the same or perhaps a more severe degree of NASH as well as a larger increase in alanine aminotransferase (ALT) levels, albeit on a longer time frame (12 weeks) [15].

FCP (NASH) diet-The FCP or NASH diet entails a HFD supplemented with $1.25 \%$ cholesterol and drinking water containing glucose and fructose $(95 \% / 45 \%, w / v)$. The FCP diet includes Western and American Lifestyle-Induced Obesity Syndrome model diets to achieve both metabolic and hepatic NASH features within 4 months. Fructose-supplemented drinking water for eight weeks results in simple steatosis in rodents without features of NASH and induces a significant increase in body weight and plasma triglyceride and glucose levels [16].

Pharmacological models

STAM-STZ-induced T2DM is a well-known experimental model of T2DM and is achieved by the administration of a low dose of STZ shortly after birth, which results in the apoptotic death of insulin-secreting pancreatic islets. When this approach is combined with HFD, it can be used as a model for NAFLD and NASH [17]. This model results in simple steatosis at 6 weeks of age, NASH with inflammatory foci and ballooning at 8 weeks, and progressive peri-cellular fibrosis starting between 8 and 12 weeks. Starting at 6 weeks of age, mice exhibit elevated ALT levels and fasting glycemia. Multiple hepatocellular carcinomas appear after 20 weeks of treatment [17].

$\mathrm{CCl}_{4}$-Supplementation of diet with $\mathrm{CCl}_{4}$ exacerbates the histological features of NASH, fibrosis, and tumor development in the setting of HFD. HFD coupled with $\mathrm{CCl}_{4}$ results in advanced fibrosis at 12 weeks and $\mathrm{HCC}$ at 24 weeks in rodent models [18].

Genetic models

Apoe-A rodent model that replicates the early stages of NAFLD is the APOE2-KI mouse in which the mouse Apoe gene is replaced by the human APOE2 allele. In addition to dyslipidemia and atherosclerosis, APOE2-KI mice develop diet-induced NASH when fed WD. A major advantage of this mouse model is that it displays good responses to pharmacological treatments [10].

Pten-PTEN is a tumor suppressor gene mutated in many human cancers, and its expression is reduced or absent in almost half of hepatoma patients, making this a relevant model for human HCC [11]. Hepatocyte-specific PTEN deficiency results in steatohepatitis and HCC in mouse models [11].

MUP-uPA mice-This model is based on feeding HFD to MUP-uPA transgenic mice, which express high amounts of uPA specifically in hepatocytes during the first 6 weeks of life [12]. HFD-fed MUP-uPA mice exhibit increased HSC activation and a substantial upregulation of collagen gene expression. Key diagnostic parameters of $\mathrm{NASH}$, including ballooning, inflammatory infiltrates and pericellular and bridging fibrosis, are evident following 4 months of HFD and are indistinguishable from human NASH, making this a relevant study model [12].

\section{Lipid Metabolism}

Hepatic steatosis is a consequence of increased hepatic lipid uptake, increased de novo lipogenesis, and reduced lipid clearance. Excessive nutrition, accompanied by hyperinsulinemia and hyperglycemia, drives steatosis by promoting de novo lipogenesis in the liver, which contributes substantially to the accumulation of triglycerides and other lipid species [19]. Hepatic lipid homeostasis is mainly regulated by peroxisome proliferator-activated receptor alpha (PPAR $\alpha), \operatorname{PPAR} \gamma, \operatorname{PPAR} \delta$ and sterol regulatory element binding protein 1c (SREBP1c), which coordinate transcriptional responses to altered metabolic conditions such as feeding and fasting to promote fat storage or catabolism, respectively. Other transcription factors of lipid metabolism that are altered in the setting of NAFLD include the constitutive androstane receptor (CAR), liver X receptor (LXR), Cyclic AMP-responsive element-binding 
protein $\mathrm{H}(\mathrm{CREBH})$, Farnesoid $X$ receptor $(\mathrm{FXR})$, signal transducer and activator of transcription 5 (STAT5), and CCAAT/enhancer binding protein alpha $(\mathrm{C} / \mathrm{EBP} \alpha)($ Table 1$)$.

Table 1. Changes in the activity of transcription factors that regulate glucose and lipid metabolism, inflammation and fibrosis in the setting of NAFLD in humans and mice.

\begin{tabular}{|c|c|c|c|c|}
\hline Factor & Model & Pathway & Regulation & Reference \\
\hline $\operatorname{PPAR} \alpha$ & Humans, mice & $\begin{array}{l}\text { Lipid metabolism, inflammation, } \\
\text { fibrosis }\end{array}$ & Upregulation & [20] \\
\hline SREBP Family & Humans, mice & Lipid metabolism & $\begin{array}{c}\text { Genetic variations increase risk } \\
\text { of NAFLD }\end{array}$ & [21] \\
\hline CAR & Humans, mice & Lipid metabolism, inflammation & Upregulation & [23] \\
\hline LXR & Humans & Lipid metabolism, inflammation & Upregulation & [24] \\
\hline FXR & Humans & Lipid metabolism & Downregulation & [25] \\
\hline STAT5 & Humans & Lipid metabolism & Upregulated & [26] \\
\hline $\mathrm{HNF} 4 \alpha$ & Humans & $\begin{array}{c}\text { Central regulator, Glucose } \\
\text { homeostasis }\end{array}$ & Downregulation & [25] \\
\hline NF- $k B$ & Humans, mice & Inflammation & Upregulation & {$[30]$} \\
\hline IRFs & Mice & Inflammation & Upregulation & [31] \\
\hline STAT1/3 & Mice & Inflammation & Upregulation & [32] \\
\hline AP-1 and c-Jun & Humans, mice & Inflammation, fibrosis & Upregulation & {$[30,33]$} \\
\hline SHP & Humans, mice & Inflammation & Downregulation & [34] \\
\hline Nrf2 & Mice & Inflammation & Upregulation & [35] \\
\hline Runx2 & Mice & Inflammation & Upregulation & [36] \\
\hline ATF6 & Humans & Metabolic stress & Upregulation & [41] \\
\hline Smad & Humans, mice & Fibrosis & Upregulation & [42] \\
\hline TGF $\beta$ & Humans, mice & Fibrosis & Upregulation & {$[42]$} \\
\hline AEBP1 & Humans, mice & Fibrosis & Upregulation & [43] \\
\hline AATF/che-1 & Humans, mice & Fibrosis & Upregulation & {$[44]$} \\
\hline YAP & Humans, mice & Fibrosis & Upregulation & [45] \\
\hline
\end{tabular}

Abbreviations: peroxisome proliferator-activated receptor (PPAR), sterol regulatory element binding protein (SREBP), carbohydrate-responsive element-binding protein (ChREBP), constitutive androstane receptor (CAR), liver $\mathrm{X}$ receptor (LXR), farnesoid X receptor (FXR), signal transducer and activator of transcription (STAT), CCAAT/enhancer binding protein (C/EBP), PPAR $\gamma$ coactivator 1 alpha (PGC1 $\alpha$ ), forkhead protein $\mathrm{O}$ (FoxO), hepatocyte nuclear factor (HNF), nuclear factor of the $\mathrm{k}$ light chain enhancer of $\mathrm{B}$ cells (NF- $\mathrm{KB}$ ), interferon regulatory factors (IRFs), activator protein 1 (AP-1), small heterodimer partner (SHP), nuclear factor erythroid 2-related factor 2 (Nrf2), runt-related transcription factor 2 (Runx2), inositol-requiring enzyme $1 \alpha(\mathrm{IRE} 1 \alpha), \mathrm{X}$ box-binding protein 1 (Xbp1), eukaryotic translation initiation factor $2 \alpha$ (eIF2 $\alpha$ ), activating transcription factor (ATF), transcription factors against decapentaplegic homolog (Smad), transforming growth factor $\beta$ (TGF $\beta$ ), adipocyte enhancer binding protein 1 (AEBP1), apoptosis antagonizing transcription factor (AATF/che-1), yes-associated protein (YAP).

\subsection{PPAR $\alpha$}

PPAR $\alpha$ belongs to the PPAR nuclear receptor family. PPAR $\alpha$ is mostly expressed in hepatocytes where it becomes activated upon binding by fatty acids (FAs) and promotes FA uptake and utilization through $\beta$-oxidation and ketogenesis [46]. Hepatic PPAR $\alpha$ expression is increased in male mice and both male and female humans with NAFLD [20,46]. Suggestive of a protective function, mice lacking 
PPAR $\alpha$ expression exhibit more severe steatosis [47]. Therefore, NAFLD-induced increases in PPAR $\alpha$ abundance can be further enhanced by its pharmacological activation: the PPAR $\alpha$ agonist WY-14643 protects mice against steatosis and steatohepatitis by preventing intrahepatic lipid and lipoperoxide accumulation [47]. Since WY-14643 causes toxicity in humans, other fibrates have been extensively used in the treatment of hypertriglyceridemia. However, these studies failed to establish benefits against NASH, which is most likely due to the widespread extrahepatic expression of PPAR $\alpha$ [48].

\subsection{PPAR}

Another member of the PPAR family, PPAR $\gamma$ is also activated by FA ligands and promotes lipogenesis and lipid accumulation. In humans and mice, two isoforms of PPAR $\gamma$ exist: PPAR $\gamma 1$ is found in nearly all tissues except muscle, while PPAR $\gamma 2$ is mostly expressed in adipose tissue and the intestine. PPAR $\gamma 2$ expression is upregulated in the liver and adipose tissue of obese humans and high-fat diet (HFD)-fed mice, whereas the PPAR $\gamma 1$ expression remains unchanged under these conditions [49]. In hepatocytes, PPAR $\gamma 1$ increases the transcription of genes that are required for FA uptake and de novo lipogenesis [50]. Meanwhile, lipidomic analyses suggest that PPAR $\gamma 2$ plays an important anti-lipotoxic role when induced ectopically in liver and muscle by facilitating the deposition of lipid droplets and preventing the accumulation of reactive lipid species, such as ceramides and pro-inflammatory lysophosphatidylcholine [51]. HFD-fed mice with a hepatocyte specific loss of PPAR $\gamma$ expression exhibit a reduction of hepatic lipid vacuoles as well as the downregulation of genes involved in de novo lipogenesis [52]. Furthermore, the liver-specific ablation of PPAR $\gamma$ in $o b / o b$ mice reduces hepatic triglycerides despite increasing serum FAs [53]. Livers of NAFLD patients have increased hepatic PPAR $\gamma$ expression $[20,46]$. Whereas increased PPAR $\gamma$ activity within hepatocytes would be expected to contribute to steatosis [54,55], the treatment of patients with the PPAR $\gamma$ agonists rosiglitazone or pioglitazone result in reduced hepatic steatosis [56-58]. This alleviation could be explained by the extrahepatic effects of PPAR $\gamma$ activation in the adipose tissue where it promotes the storage of excess energy in the form of lipid droplets, thereby limiting exposure of the liver to excess lipids.

\subsection{PPAR}

Similar to other PPARs, PPAR $\delta$ binds to the PPAR response element (PPRE) to initiate or repress the expression of target genes [59]. PPAR $\delta$ is ubiquitously expressed and is activated by polyunsaturated fatty acids and their metabolites. In mouse livers, PPAR $\delta$ prevents lipid accumulation by increasing $\beta$-oxidation and autophagy. In addition, the activation of PPAR $\delta$ in the adipose tissue of mice upregulates the expression of genes involved in $\beta$-oxidation and energy dissipation [60,61]. Recent clinical studies using PPAR $\delta$ agonists atorvastatin and cardarine reduced hepatic fat content in overweight patients with mixed dyslipidemia [61,62].

\subsection{SREBP}

The SREBP family transcription factors consist of three isoforms: SREBP1a, SREBP1c, and SREBP2. Each isoform exhibits a different tissue expression pattern and metabolic control [63]. SREBP1a is the predominant isoform in the intestine, spleen, and cultured cells, while SREBP1c and SREBP2 exhibit higher abundance in the liver [63]. SREBP1a is a potent activator of genes that mediate the synthesis of cholesterol, fatty acids, and triglycerides. The roles of SREBP1c and SREBP2 are more restricted than those of SREBP1a. SREBP1c promotes the transcription of genes involved in lipogenesis, such as acetyl-coenzyme A (CoA) carboxylase (ACC), FA synthase (FASN), and steroyl-CoA desaturase in response to insulin and high-energy state [64]. By contrast, hepatic markers for energy deprivation, such as glucagon signaling (protein kinase A [PKA], AMP activated protein kinase [AMPK]) and the deacetylase sirtuin1 (SIRT1) inhibit SREBP1c, suggesting that SREBP1c does not promote hepatic lipid synthesis in the setting of starvation [65]. Among the genes involved in lipogenesis, SREBP1c also promotes the transcription of patatin-like phospholipase3 (PNPLA3), which in turn stimulates lipid 
accumulation [66]. Independent studies in humans have confirmed that PNPLA3 variants are strongly associated with the severity of NAFLD and NASH [67-69]. SREBP1c is upregulated in the livers of humans and mice with NAFLD [70]. Interestingly, there is also a positive correlation between single nucleotide polymorphisms (i.e., rs2297508) as well as rare variants of SREBP1 with the risk of developing NAFLD [21]. Unlike SREBP1c, SREBP2 preferentially activates cholesterol synthesis [71]. In mice, SREBP2 contributes to the onset of NASH by triggering cholesterol accumulation [72]. Increased hepatic SREBP2 is also associated with increased free cholesterol in NASH patients [73].

\section{5. $C A R$}

CAR is a member of the nuclear receptor superfamily [74]. It mainly functions as a sensor of endobiotic and xenobiotic substances, as CAR-activated genes regulate drug metabolism and enhance bilirubin clearance [74]. Unlike most nuclear receptors, this transcriptional regulator is constitutively active in the absence of a ligand. CAR activity is anti-obesogenic and improves insulin sensitivity [75]. The metabolic benefits of CAR activation stem from the combined effects of reduced lipogenesis, very low-density lipoprotein (VLDL) secretion, and gluconeogenesis, as well as increased peripheral fat mobilization for thermogenesis in brown adipose tissue [75]. The anti-steatotic effect of CAR was first demonstrated using a mouse model with the genetic ablation of cytoplasmic CAR retention protein (CCRP), which isolates CAR to the cytosol and inactivates it. Subsequent CAR activation represses lipogenic gene expression and increases $\beta$-oxidation [76]. Similar to mouse models of NAFLD, CAR is also upregulated in the livers of patients with NAFLD [23].

\section{6. $L X R$}

LXR is a member of the nuclear receptor family of transcription factors that is closely related to PPARs [77]. LXR forms heterodimers with the obligate partner retinoid X receptor (RXR), which is activated by retinoic acid and cholesterol derivatives. LXR is an important regulator of cholesterol, FA, and glucose homeostasis [77]. LXR activation increases hepatic triglyceride accumulation and cholesterol metabolism in both humans and mice and initiates bile acid degradation in mice [78]. Humans express two LXR family members, namely LXR $\alpha$ (NR1H3) and LXR $\beta$ (NR1H2). LXR $\alpha$ expression increases by 2- and 3-fold in the livers of NAFLD and NASH patients, respectively, compared to healthy controls [24]. Furthermore, LXR $\alpha$ expression positively correlates with the amount of hepatic fat and hepatic expression of the cholesterol transporter ATP-binding cassette sub-family $G$ member 5 (ABCG5/8), the FA transporter cluster of differentiation 36 (CD36), and SREBP1c [24].

\section{7. $C R E B H$}

CREBH is primarily expressed in the endoplasmic reticulum (ER) of cells in the liver and small intestine [79,80]. CREBH expression increases in response to fasting through glucagon signaling [81]. CREBH expression is also controlled by the binding of glucocorticoid or PPRE to its promotor region [82]. Therefore, CREBH expression can be induced by a variety of PPAR $\alpha$ agonists such as palmitate and oleate [82]. ER-anchored CREBH becomes activated in response to hepatic lipid accumulation and VLDL assembly. The activation of CREBH requires ER-to-golgi trafficking followed by proteolytic cleavage and nuclear translocation $[81,83,84]$. CREBH activates a group of genes that are involved in TG and lipoprotein production $[85,86]$. CREBH also binds to and functions as a co-activator for both PPAR $\alpha$ and LXR $\alpha$ to promote FA uptake and utilization [86]. CREBH-deficient mice are susceptible to hepatic steatosis following fasting [81] or diets with high-fat content [79,86]. Interestingly, the livers of CREBH-deficient mice exhibit the reduced expression of genes that promote de novo lipogenesis and FA elongation [86]. Observed steatosis most likely arises from the reduced hepatic expression of genes involved in FA oxidation and increased lipolysis in the adipose tissue, resulting in an increased flow of FA from adipose tissue to the liver [79]. Furthermore, fibroblast growth factor (FGF) 21 is a critical CREBH target that reduces hepatic lipid storage. CREBH overexpression in the livers of mice suppresses hepatic lipid accumulation by increasing FGF21 secretion [87]. 


\subsection{FXR}

FXR is a major member of the ligand-activated nuclear receptor superfamily [78]. The family consists of four isoforms namely, FXR $\alpha 1$, FXR $\alpha 2$, FXR $\beta 1$, and FXR $\beta 2$ [88]. Similar to LXR, bile acids are natural ligands for FXR, which plays an important role in regulating bile acid homeostasis, glucose and lipid metabolism, intestinal bacterial growth, and hepatic regeneration [89]. While LXR facilitates the storage of carbohydrate- and fat-derived energy, FXR decreases TG levels and improves glucose metabolism [90]. One of the primary functions of FXR activation is the suppression of CYP7A1, the rate-limiting enzyme in bile acid synthesis from cholesterol [91]. FXR expression is decreased in NASH patients [25], which can aggravate the development of steatosis and NASH: (1) FXR activation represses hepatic lipogenesis via the FXR-SHP-SREBP1c pathway (see below for more on small heterodimer partner [SHP]), (2) FXR activation promotes $\beta$-oxidation by stimulating the expression of PPAR $\alpha$ and CPT1, and (3) FXR activation reduces hepatic FA uptake by reducing the expression of CD36 [89].

\subsection{STAT5}

STAT5 belongs to a family of intracellular transcription factors that are activated by membrane receptor-associated Janus kinases (JAK). The growth hormone (GH)-mediated activation of STAT5 [92] plays an important role in hepatic fat metabolism through the downregulation of CD36 [93]. The liver-specific loss of STAT5 in mice induces hepatic steatosis following a HFD [92]. These mice also exhibit hyperglycemia, hyperinsulinemia, hyperleptinemia, and elevated free FA and cholesterol concentrations following HFD. At the transcriptional stage, the loss of STAT5 results in the transcription of genes involved in lipid uptake (CD36), VLDL uptake (very low-density lipoprotein receptor), and lipogenesis (stearoyl-CoA desaturase and PPAR $\gamma$ ) [93]. However, it is unclear whether STAT5 directly regulates the expression of these factors. In addition, its relevance in human steatosis associated with GH-deficiency is yet to be established.

\subsection{0. $C / E B P \alpha$}

C/EBP $\alpha$ belongs to a transcription factor family of six members which are involved in a variety of cellular responses [94]. C/EBP $\alpha$ plays a role in lipogenic gene expression by inducing the expression of $\operatorname{PPAR} \gamma$ [95]. The liver-specific ablation of $\mathrm{C} / \mathrm{EBP} \alpha$ reduces lipogenic gene expression and triglycerides in the livers of leptin-deficient $o b / o b$ mice, which otherwise display severe steatosis [95]. These findings were confirmed by a similar observation of reduced hepatic gene expression following siRNA-mediated inhibition of C/EBP $\alpha$ expression in the livers of leptin receptor-deficient $(d b / d b)$ mice [27].

\section{Glucose Metabolism}

The liver does not only play a central role in systemic lipid homeostasis but also regulates the glucose balance in circulation. This is mediated by the activation of carbohydrate-responsive element-binding protein (ChREBP) in response to increases in plasma glucose and the nuclear localization of PPAR $\gamma$ coactivator 1 alpha (PGC1 $\alpha$ ), cAMP response element binding protein (Creb), CREBH, forkhead protein O1 (FOXO1), and hepatocyte nuclear factor $4 \alpha$ (HNF4 $\alpha$ ) in response to fasting to promote hepatic glucose production [96] (Table 1). Furthermore, PPAR $\delta$ also plays a role in glucose homeostasis. The exacerbation of hepatic glucose production coupled with hyperglycemia and insulin resistance play an important pathogenic role in NAFLD.

\subsection{ChREBP}

ChREBP consists of ChREBP $\alpha$, the full-length isoform, or ChREBP- $\beta$, the truncated isoform [97]. ChREBP $\alpha$ is directly activated by glucose, independently from insulin signaling [98]. Little is known about ChREBP $\beta$, which was reported to be expressed in a glucose- and ChREBP-dependent manner whereby glucose-activated ChREBP $\alpha$ initiates ChREBP $\beta$ transcription from an alternate promoter [99]. 
In the liver, ChREBP promotes glycolysis and lipogenesis. ChREBP expression is increased in the livers of NASH patients with advanced steatosis [100]. By contrast, decreased ChREBP expression is associated with severe insulin resistance [22]. This pattern indicates that ChREBP is essential for the storage of excess glucose as triglycerides. In fact, mice that overexpress ChREBP exhibit improved insulin sensitivity and glucose tolerance despite having more pronounced hepatic steatosis. Together, these studies have demonstrated that increased ChREBP activity improves insulin sensitivity by promoting simple steatosis without lipotoxicity [22].

\section{2. $P G C 1 \alpha$}

The PGC1 family of transcriptional co-activators play a central role in the regulation of metabolism. The PGC1 family consists of three members, namely PGC1 $\alpha$, PGC1 $\beta$, and the PGC-related co-activator (PRC), which interact with transcription factors and nuclear receptors to exert their biological functions. PGC1 $\alpha$ expression is induced by metabolic cues such as exercise, cold, and fasting [101]. The activation of PGC1 $\alpha$ in the liver drives the expression of genes that are essential to gluconeogenesis, FA oxidation, lipid transport, and mitochondrial biogenesis. The activity of PGC1 $\alpha$ becomes impaired in the setting of liver injury and steatosis in mice, and the loss of PGC1 $\alpha$ has been linked to the increased susceptibility to NAFLD in HFD-fed mice [102]. PGC1 $\alpha$ haploinsufficiency in mouse liver inhibits $\beta$-oxidation and increases triglyceride synthesis, leading to hepatic steatosis and insulin resistance. Similarly, PGC1 $\alpha$ overexpression in rat hepatocytes results in reduced concentrations of hepatic triglycerides in vitro and in vivo, due to increased $\beta$-oxidation [28].

\subsection{CREB}

CREB becomes activated in response to glucagon-mediated increases in cellular cAMP. The knockdown of CREB dramatically reduces fasting plasma glucose concentrations in several rodent models for obesity and type 2 diabetes, including Zucker diabetic fatty (ZDF) rats, STZ-treated/HFD-fed rats, and $o b / o b$ mice. CREB does not only promote the expression of gluconeogenic genes but also increases plasma TG and cholesterol concentrations as well as hepatic steatosis by activating de novo lipogenesis in the liver [103].

\subsection{CREBH}

CREBH was reported to bind and upregulate genes that contain cAMP-responsive elements, including phosphoenolpyruvate carboxykinase 1 (Pck1) and glucose-6-phosphatase (G6Pase) [80,81], which are essential promoters of gluconeogenesis. CREBH also upregulates the rate-limiting enzyme for hepatic glycogenolysis, namely glycogen phosphorylase (Pygl) [81]. Consequently, CREBH overexpression in the livers of mice increases plasma glucose levels, while its knockdown reduces circulating glucose [81].

\subsection{FOXO}

The forkhead protein family comprises of more than 100 members in humans and are enumerated FOXA to FOXR based on their sequence similarity [104]. The members of the FOXO subfamily, which consists of FOXO1, FOXO3, FOXO4, and FOXO6, are regulated by insulin signaling whereby Akt-mediated phosphorylation sequesters FOXOs within the cytosol, inhibiting their transcriptional activity in the nucleus [105]. FOXO family members mediate the expression of genes that play a role in cell death, DNA repair, glucose, and energy metabolism [106]. Hepatic FOXO1 regulates the expression of both gluconeogenic and lipogenic genes. Under fasting conditions, FOXO1 drives the expression of gluconeogenic enzymes. In addition, FOXO1 induces the transcription of genes involved in the hepatic assembly of VLDL, reducing hepatic steatosis [106]. The genetic ablation of FOXO increases susceptibility to NAFLD and NASH in mice [105]. Specifically, the deletion of FOXO1/3 or FOXO1/3/4 genes in mouse livers leads to mild or moderate hepatic steatosis, even when mice are maintained on a regular chow diet [105]. Exposing the mice to HFD supplemented with cholesterol further exacerbates 
steatosis in FOXO1/3/4-deficient mice [105]. Conversely, the overexpression of a constitutively active FOXO1 reduces hepatic triglycerides [105]. On the other hand, livers of NASH patients exhibit a greater expression of FOXO1 compared to patients with simple steatosis as well as metabolically healthy patients with and without obesity [29]. More investigation into FOXO1 activity during different stages of human liver disease is needed to establish mechanisms and physiological relevance.

\section{6. $H N F 4 \alpha$}

$\mathrm{HNF} 4 \alpha$ is a member of the nuclear hormone receptor superfamily and has been shown to play an essential role in maintaining bile acid, lipid, and glucose homeostasis. HNF4 $\alpha$ translates extracellular endocrine signals and intracellular stress and nutritional state onto transcriptional responses in the liver. HNF4 $\alpha$ is regulated by growth hormone, glucocorticoids, thyroid hormone, insulin, transforming growth factor beta (TGF $\beta$ ), estrogen, and cytokines [107]. HNF4 $\alpha$ target genes have been identified in the liver, pancreas, and colon. In the liver, the targets include genes involved in glucose (PEPCK, glucose-6-phosphatase (G6Pase)), bile (CYP7A1), xenobiotics and drug metabolism (CYP3A4, CYP2D6, and CYP2E1) [108]. HNF4 $\alpha$ also regulates circulating levels of cholesterol and triglycerides by inducing the transcription of genes that encode for apolipoproteins. HFD-induced oxidative stress promotes hepatic steatosis by blocking the activity of HNF4 $\alpha$ in mice [109]. The expression of HNF4 $\alpha$ is decreased in NASH patients [25]. Furthermore, a systematic integrative analysis of gene transcription has identified HNF4 $\alpha$ as 'the central gene' in the NASH pathogenesis [25].

\subsection{PPAR}

In addition to its activation of fatty acid oxidation, PPAR $\delta$ improves glucose homeostasis and protects from insulin resistance by promoting insulin secretion in the pancreatic islet $\beta$-cells $[110,111]$ and by increasing energy utilization [112]. Mice lacking PPAR $\delta$ expression have reduced energy expenditure and are glucose-intolerant. In contrast, receptor activation by GW50516, a PPAR $\delta$-specific agonist, suppresses hepatic glucose output, improves insulin sensitivity and increases glucose disposal in mice [112]. This increase in energy disposal has been linked to increased $\beta$-oxidation in the skeletal muscle of mice following GW50516 treatment [113].

\section{Inflammation}

The hepatic inflammatory response is an important driving force for NASH progression as it promotes sustained hepatic fibrogenesis. Transcription factors activated in response to inflammatory stimuli mainly belong to the family of nuclear factor of the $\kappa$ light chain enhancer of B cells (NF- $k B s$ ), interferon regulatory factors (IRFs), STAT, and activator protein 1 (AP-1) [114]. Other factors that have also been implicated in the transcriptional regulation of the inflammatory response include apoptosis antagonizing transcription factor (AATF, synonym: che-1), SHP, Runt-related transcription factor 2 (Runx2), and C/EBP $\beta$. In addition to inflammation-specific regulators, transcriptional regulators of lipid homeostasis PPAR $\alpha, \operatorname{PPAR} \gamma, \mathrm{CAR}$, and LXR also affect the hepatic inflammatory state (Table 1).

\section{1. $N F-\kappa B$}

NF- $\mathrm{kB}$ is a protein complex that controls cytokine production and cell survival, and as such, it plays a key role in the immune response to infection. NF- $\kappa B$ is also critical for the development of inflammation in various metabolic disorders such as T2DM [115] and is highly activated in both mice and patients with NASH $[30,116]$. The pharmacological inhibition of NF-kB signaling protects MCD-fed mice from the pathogenesis of NASH with significant reductions in hepatocellular injury and hepatic inflammation. Furthermore, the stage of inflammation and fibrosis in livers of NASH patients correlates with the expression of the p65 subunit of NF-kB [117]. 


\subsection{IRFs}

IRFs are a family of transcription factors that regulate the transcription of interferons and consist of nine members. Most IRFs are involved in innate immunity and defense against pathogens. IRF family members impose variable impacts on inflammation in the pathogenesis of NAFLD. Studies using mice with the deletion of IRF7 expression indicated that IRF7 promotes weight gain, hepatic fat deposition, and insulin resistance in the setting of HFD [118]. In contrast, a similar study using IRF9-deficient mice demonstrated that IRF9 promotes insulin sensitivity and attenuates inflammation and hepatic steatosis [119]. Interestingly, IRF9 was shown to interact with PPAR $\alpha$ and activate its target genes [119].

\subsection{STAT}

STAT family members with inflammatory biological functions (STAT1 and STAT3) have been associated with NAFLD and NASH. The oxidative hepatic environment in obesity inhibits the STAT1 and STAT3 phosphatase, T cell protein tyro-sine phosphatase (TCPTP), which results in increased STAT1 and STAT3 signaling. This in turn increases the risk of developing NASH and HCC in the setting of excessive nutrition [32]. Furthermore, the inactivation of TCPTP, coupled with increased STAT1 and STAT3 signaling, are easily detectable events in the livers of humans with NASH [32].

\subsection{AP1}

AP1 activation requires the synthesis of c-Jun and c-Fos proteins and c-Jun phosphorylation by c-Jun N-terminal kinase (JNK) for the full transactivation of target genes. Obese patients with NASH exhibit an enhanced hepatic expression of AP1 targets [30]. JNK activation and the extent of c-Jun nuclear localization correlates very well with the pathogenesis and progression of NASH in humans and mouse models [33]. Activated c-Jun promotes nuclear accumulation of JNK, which provides a positive feedback loop to further enhance AP1 transcriptional activity and exacerbate NASH progression [120,121].

\subsection{AATF}

AATF mediates cell proliferation and survival [122-124]. Its expression in the liver increases with simple steatosis [44]. Indicative of a role in inflammation, AATF expression increases in response to tumor necrosis factor $\alpha(\mathrm{TNF} \alpha)$-mediated activation of SREBP1 in cultured cells. In turn, AATF induces the expression of the inflammatory cytokine monocyte chemotactic protein 1 (MCP1) by activating STAT3. Hepatic AATF expression does not increase any further with disease progression to NASH [44], suggesting that it plays a role in exacerbating simple steatosis toward the pathogenesis of inflammatory stages of steatohepatitis. However, its contribution to the progression of NASH to advanced stages remains unclear.

\subsection{SHP}

SHP is technically not a transcription factor, since it lacks a DNA binding domain but is still classified as such due to its sequence homology to other nuclear receptor families. The principal role of SHP is the repression of other nuclear receptors by binding and forming a dysfunctional heterodimer. SHP is a critical repressor of various genes involved in glucose and lipid metabolism and bile acid synthesis [125]. Several factors indicate a role in inflammation: first, SHP inhibits inflammatory responses that are triggered by the Toll-like receptor (TLR) [126] as well as the NLR family pyrin domain containing 3 (NLRP3) inflammasome, which consists of a multimeric protein complex that triggers inflammatory cell death and the release of pro-inflammatory cytokines interleukin (IL)-1 $\beta$ and IL-18 [127]. In addition, SHP suppresses inflammation by inhibiting transcription of the chemokine CCL2 whose biological function is to recruit macrophages and promote inflammation [34]. The SHP-mediated mitigation of inflammatory responses could play a protective role in NASH. SHP expression is drastically decreased in the livers of a mouse model of NASH and in the livers of 
NASH patients compared healthy or steatotic livers [34]. The rescue of SHP expression in the livers of mice prevents the progression of NAFLD to NASH [34]. Mechanistically, the reduction of SHP expression in NASH was linked to inhibitory binding of c-Jun to the SHP promoter, suggesting that the JNK/SHP/NF-KB/CCL2 axis is a promising target for NASH prevention and treatment.

\subsection{Runx2}

Runx2 plays an important role in atherosclerosis. It has been indicated that atherosclerosis shares a similar histopathology with NASH with respect to macrophage infiltration. Indeed, experiments in mouse primary HSCs have elucidated a mechanism whereby Runx 2 within HSCs promotes macrophage infiltration by increasing the transcription of MCP1 [36].

\subsection{C/EBP $\beta$}

C/EBP $\beta$ was originally identified as nuclear factor interleukin-6 (NFIL6) because of its inducibility by IL- 6 and its important role in the activation of acute inflammatory response genes in human hepatoma cells [128]. The livers of mice lacking C/EBP $\beta$ express reduced markers of inflammation and endoplasmic reticulum (ER) stress and exhibit decreased steatosis following an MCD diet. By contrast, $\mathrm{C} / \mathrm{EBP} \beta$ overexpression increases the hepatic prevalence of PPAR $\gamma$, ER stress, NF- $\mathrm{kB}$ activation, and steatosis [27].

\subsection{PPAR $\alpha$}

In addition to its role in the regulation of metabolism, PPAR $\alpha$ also exhibits anti-inflammatory effects through its regulation of NF-KB [129]. The treatment of non-steatotic mice with the PPAR $\alpha$ agonist WY-14643 decreases the hepatic inflammatory gene expression profile, suggesting a direct anti-inflammatory effect of PPAR $\alpha$ independent of changes in liver triglycerides [130].

\subsection{PPAR $\gamma$}

Hepatic PPAR $\gamma$ does not only regulate hepatocyte metabolism but also plays an important regulatory role in liver-resident macrophages (Kupffer cells), where it acts as an inhibitor of macrophage activation and cytokine production. This regulation is mediated through the PPAR $\gamma 1$-mediated inhibition of AP-1, STAT, and NF- $\mathrm{kB}$, which are the major regulators of macrophage activation and TNF $\alpha$ synthesis [131]. Mice with Kupffer cell-specific loss of PPAR $\gamma$ expression exhibit increased hepatic expression of inflammatory cytokines TNF $\alpha$ and IL1 $\beta$ and fibrosis in response to $\mathrm{CCl}_{4}$-induced liver injury [132]. Conversely, PPAR $\gamma$ induction by rosiglitazone decreases the number of hepatic Kupffer cells, attenuating the inflammatory response as well as steatosis in a diet-induced mouse model of NAFLD [133].

\subsection{CAR}

CAR activation can potentially be used to delay or reduce the progression of NAFLD due to its dual anti-steatotic and anti-inflammatory effects. In the MCD mouse model of NASH, the administration of the CAR agonist 2,2'-[1,4-phenylenebis(oxy)]bis[3,5-dichloro]-pyridine (TCPOBOP) reduces inflammation and hepatocellular apoptosis by reducing the accumulation of Kupffer cells and enhancing the hepatic clearance of pro-inflammatory leukotriene B4 [134]. On the other hand, CAR knockout mice exhibit improved lipid peroxidation and hepatic fibrosis after exposure to the MCD diet [135]. Therefore, the precise role of CAR in the pathophysiology of NASH requires additional studies.

\subsection{LXR}

Although LXR promotes inflammation, its impact on obesity and steatosis is inconsistent. Mouse models with the deletion of LXR expression have indicated that LXR decreases inflammation by inhibiting the transcription of TNF $\alpha$, IL-6, and IL-1 $\beta$ but increases steatosis [136]. On the other 
hand, the treatment of mice with the LXR antagonist SR9238 generates both anti-steatotic [137] and anti-fibrotic effects [138] with a dramatic reduction in steatosis, inflammation, and collagen disposition in the livers of mice. Overall, all studies indicate that LXR could be a valuable target for the treatment and prevention of NASH.

\section{Metabolic Stress}

The pathogenesis of NAFLD does not only depend on energy metabolism and inflammation but has also been mechanistically linked to increased cellular stress. Upon excessive nutrition, the ER cannot meet high metabolic demands and initiates the unfolded protein response (UPR) by activating three transmembrane factors located on the ER membrane: protein kinase R-like ER kinase (PERK), inositol-requiring enzyme $1 \alpha$ (IRE1 $\alpha$ ), and activating transcription factor 6 (ATF6). PERK activates eukaryotic translation initiation factor $2 \alpha(\mathrm{eIF} 2 \alpha)$, which in turn activates ATF4. Meanwhile, IRE1 $\alpha$ splices the mRNA of X box-binding protein 1 (Xbp1) to its active isoform Xbp1s. ATF4, ATF6, and Xbp1 together initiate transcriptional events to resolve ER stress. However, excessive reactive oxygen species (ROS) and ER stress due to excessive lipid accumulation in the liver can lead to inflammation and hepatocyte death [139]. For instance, increased CYP2E1 expression promotes ROS production and the progression of NAFLD. In contrast, stress-induced activation of nuclear erythroid 2-related factor 2 (NRF2) protects against oxidative stress and the pathogenesis of NAFLD [140]. Furthermore, unresolved ER stress results in the activation of apoptotic transcription factor CCAAT/enhancer binding protein (CHOP). The prolonged activation of IRE1 $\alpha$ also leads to the activation of the inflammatory transcription factors c-Jun and NF- $\mathrm{kB}$. Thus, the transcription factors involved in stress-induced responses may contribute to the development of NASH (Table 1).

\section{1. $\mathrm{Xbp} 1$}

High caloric stress leads to the splicing and nuclear localization of Xbp1, which in turn transcribes factors that improve protein folding as well as lipogenesis [38]. However, obesity-induced chronic stress limits the nuclear localization of Xbp1 and aggravates ER stress and insulin resistance [141]. The rescue of Xbp1 activity in HFD-fed or ob/ob mice improves glucose homeostasis and reduces hepatic steatosis, which is associated with reductions in the expression of lipogenic genes [142]. Whether the improvement of hepatic steatosis in these mouse models is a direct outcome of transcriptional regulation by $\mathrm{Xbp} 1$ or a secondary consequence of resolved metabolic stress and improved insulin sensitivity remains unclear. Nonetheless, the lipogenic role of $\mathrm{Xbp} 1$ is demonstrated using a mouse model with a liver-specific ablation of $\mathrm{Xbp} 1$ following $\mathrm{WD}$, whereby the loss of $\mathrm{Xbp} 1$ is associated with reduced steatosis but enhanced liver injury and fibrosis with the upregulation of type-I collagen $\alpha 1$ (Col $\alpha 1)$, TGF $\beta 1$, CHOP, and p-JNK [38,143].

\subsection{ATF4}

In NASH patients, the mRNA expression of ATF4 and CHOP and protein expression of $\mathrm{CHOP}$ are significantly elevated compared to liver samples from patients with simple steatosis [40]. ATF4 depletion protects mice from high fructose-induced hepatic steatosis by reducing lipogenesis through the reduced hepatic expression of PPAR $\gamma$, SREBP1c, ACC, and FASN [144].

\subsection{ATF6}

Hepatic ATF6 knockdown or overexpression of its dominant-negative form by adenovirus in WD-fed mice exacerbates insulin resistance and hepatic steatosis with reduced transcriptional activity of the PPAR $\alpha / R X R$ complex. Conversely, overexpression of the cleaved active from of ATF6 protects mice from hepatic steatosis and promotes hepatic FA oxidation. Experiments in hepatocytes have shown that ATF6 promotes hepatic FA oxidation by enhancing PPAR $\alpha$ transcriptional activity through direct interaction and activates its downstream targets such as carnitine palmitoyltransferase 1 alpha 
$(\mathrm{CPT} 1 \alpha)$ and medium-chain acyl-CoA dehydrogenase (MCAD) [145]. Activated ATF6 also interacts with SREBP2 and inhibits SREBP2 target genes in hepatocytes [146].

\subsection{NRF2}

NRF2 is the primary driver of gene expression via the antioxidative response elements (ARE). In response to oxidative damage such as lipid peroxidation and DNA damage, NRF2 increases the transcription of antioxidative factors, including $[140,147]$ NRF2, which suppresses inflammation by preventing the increased transcription of pro-inflammatory cytokines [140]. Specifically, NRF2 interferes with the lipopolysaccharide-induced transcriptional upregulation of IL- 6 and IL-1 $\beta$. Accumulating evidence supports a protective role of NRF2 in NASH [148]. In rats and mice with diet-induced NASH, NRF2 activation improves glucose homeostasis and inhibits hepatic steatosis, inflammation, and fibrosis by decreasing lipid synthesis and upregulating $\beta$-oxidation and lipoprotein assembly $[35,149]$. In contrast, the loss of NRF2 exacerbates hepatic steatosis and accelerates the development of NASH in mice fed an HFD or MCD $[150,151]$. Mechanistically, the oxidative stress due to the deletion of NRF2 in these mice activates NF- $\mathrm{kB}$ and leads to the upregulation of the inflammatory cytokines IL- 6 and TNF $\alpha$.

\subsection{CYP2E1}

Although it is not a transcription factor, it is important to include CYP2E1, which becomes activated following insulin resistance and lipotoxicity [152] and promotes ROS production in the setting of NAFLD [153]. CYP2E1 plays key metabolic roles in gluconeogenesis and fatty acid metabolism. It controls the formation of lactate or glucose from the ketone body acetone [154]. Furthermore, CYP2E1 carries out the omega hydroxylation of fatty acids, increasing lipotoxicity and inflammation [155], which represent major pathophysiological mechanisms in NAFLD progression [156]. The role of CYP2E1 in liver injury was first identified following the alcohol-induced induction of CYP2E1 protein. However, clear differences exist between alcoholic liver disease (ALD)- and NAFLD-induced activation of CYP2E1: while alcohol consumption only stabilizes the CYP2E1 protein without changes in mRNA expression, excessive nutrition increases both protein stability and mRNA abundance [157]. Although the transcriptional regulation of CYP2E1 has been linked to the activities of HNF1 $\alpha$ [158], HNF4 $\alpha$ [108], SP1 [159], and C/EBP [154], the mechanisms by which obesity and NAFLD exacerbate CYP2E1 activity requires additional studies [153].

\section{Fibrosis}

Fibrosis is the strongest predictor of adverse clinical outcomes for NASH. Fibrogenesis during liver injury is initiated by the activation of HSCs in the liver [160,161]. Established inducers of fibrogenesis and HSC activation include adipocyte enhancer binding protein 1 (AEBP1), AATF, yes-associated protein (YAP), and transforming growth factor beta-(TGF $\beta$ )-mediated activation of transcription factors against decapentaplegic homolog (SMAD). In addition to these fibrosis-specific regulators, the main transcriptional regulators of lipid homeostasis (including PPAR $\alpha$ and PPAR $\gamma$ ) and inflammation (RUNX2 and c-Jun) have also been reported to dictate the fibrotic stage in NASH (Table 1).

\subsection{TGFB/SMAD axis}

TGF $\beta$ is secreted from activated HSC and is a potent inducer of fibrogenesis. Its pro-fibrogenic effect is mainly mediated by the TGF $\beta$ receptor (TGF $\beta R$ )-dependent activation of the SMAD family in HSC: the phosphorylated SMAD2/3 complex binds to SMAD4 and translocates to the nucleus to promote the transcription of fibrogenic genes including $\operatorname{Co} 1 \alpha 1, \operatorname{Co} 3 \alpha 1$, smooth muscle alpha 2 actin ( $\alpha$ SMA), and TGF $\beta$ as well as the production of tissue inhibitor of metalloproteinases (TIMPs) [162], which promote fibrosis by inhibiting matrix degradation [163]. In contrast, Smad7 inhibits the regulation of the TGF $\beta$ signaling by recruiting ubiquitin E3 ligases that promote the degradation of TGF $\beta R 1$ and by recruiting the protein phosphatase PP1C, which inactivates TGF $\beta$ R1 [164]. The livers of NASH patients as well as a mouse model of NASH exhibit increased nuclear localization of the 
SMAD2/3/4 complex and the reduced expression of SMAD7, which all together contribute to increased TGF $\beta$, Co1 $\alpha 1$, and $\alpha$ SMA [42]. The regulation of SMAD2/3 has also highlighted the role of additional transcription factors in mediating TGF $\beta$-mediated fibrogenesis: the interactions of the transcriptional coactivators CREB binding protein (CBP) and p300 with SMAD2/3 promotes histone acetylation and increased transcriptional activity [165]. Supporting the pathophysiological relevance of this axis, the AMPK-mediated degradation of p300 results in the inhibition of TGF $3 /$ SMAD3-mediated fibrogenesis in HSC [166]. Finally, the transcription factor v-ets avian erythroblastosis virus E26 oncogene homolog 1 (ETS1), which is elevated in a NASH mouse model, enhances TGF $\beta /$ SMAD signaling by directly binding to SMAD3 and preventing its ubiquitination and degradation [167].

\section{2. $A E B P 1$}

AEBP1 plays a role in adipogenesis [168,169], myofibroblast differentiation [170], and macrophage cholesterol homeostasis [171]. AEBP1 was identified as a key transcription factor during the transition from simple steatosis to NASH using a co-regulatory network approach, which assessed AEBP1 expression in NASH fibrosis versus other NAFLD histological classes using pairwise comparisons [172]. In support of this database analysis, AEBP1 expression increases in the setting of NASH compared to simple steatosis in the livers of $A p o E^{+/-}$mice. A recent clinical study demonstrated that AEBP1 is specifically expressed in HSC and at a greater extent in the livers of patients with NASH [43]. The ablation of AEBP1 only in the HSC of mice protects against high fat and high cholesterol diet-induced fibrosis. Mechanistically, AEBP1 activates Wnt signaling by specifically binding frizzled-8 and low-density lipoprotein-related receptor 6, which blocks the PPAR $\gamma$-dependent inhibition of activated HSC. Another study confirmed that hepatic AEBP1 is directly associated with the degree of steatosis, lobular inflammation, and fibrosis in NASH patients [168]. This study also found that AEBP1 upregulates the expression of genes identified as part of an algorithm-predicted AEBP1-associated NASH co-regulatory network [168]. These target genes include the regulators of fibrosis (AKR1B10, CCDC80, DPT, EFEMP1, ITGBL1, LAMC3, MOXD1, SPP1, and STMN2), ECM production and maintenance (COL4A2 and MARCO), and myofibroblast transition (ACTA2, COL1A1, COL1A2, SERPINE1 and PLAU). Taken together, these findings strongly implicate AEBP1 in the diagnosis and treatment of NASH.

\subsection{YAP}

The Hippo pathway and its effector YAP are particularly important for controlling liver size by regulating proliferation and growth [173]. The expression of YAP is barely detectable in healthy livers of humans and mice but becomes activated in the setting of NASH [45]. YAP is expressed in hepatocytes and activates the expression of proteins that promote fibrosis (ColL1 $\alpha 1$, TIMP1, TGF $\beta 2$ ) and inflammation (TNF $\alpha, \mathrm{IL}-1 \beta)$, which stimulate the expansion of myofibroblasts and the recruitment of immune cells, exacerbating liver fibrosis [174]. YAP is also activated in Kupffer cells by the lipopolysaccharides (LPS)/TLR4 signaling pathway, where it promotes the development of NASH by enhancing the production of pro-inflammatory cytokines [175]. Further gain and loss of function experiments have shown that the activation of the YAP/transcriptional co-activator with PDZ-binding motif (TAZ) axis leads to the expression of a key matricellular chemokine (CYR61), which stimulates and recruits extrahepatic macrophages to promote liver fibrosis.

\subsection{PPAR $\alpha$}

In addition to beneficial effects on steatosis and inflammation, PPAR $\alpha$ agonist treatment also reverses fibrosis by targeting PPAR $\alpha$ in HSC, which decreases the expression of fibrogenic factors including Col1 $\alpha 1$ and TIMPs and reduces the number of activated HSC. The protective effect of PPAR $\alpha$ was further demonstrated by treating fibrotic $\mathrm{APOE}_{2} \mathrm{KI} 1811 \mathrm{~A}$ mice with the PPAR $\alpha$ agonist fenofibrate, which protected mice from NASH by reducing both steatosis and hepatic macrophage 
accumulation [10]. By contrast, mice with a genetic ablation of PPAR $\alpha$ display increased susceptibility to NASH [130,176].

\subsection{PPAR $\gamma$}

In humans, growth factors activate HSC that display decreased PPAR $\gamma$ expression during the progression of NAFLD to NASH [160]. On the other hand, livers with simple steatosis exhibit increased PPAR $\gamma$ expression. The treatment of rats with NASH with the PPAR $\gamma$ agonist pioglitazone prevents hepatic fibrosis and reduces the expression of TIMPs [177]. Indicating that the inhibition of PPAR $\gamma$ in HSC is responsible for the increased transcription of TIMPs, the overexpression of PPAR $\gamma$ reduces the expression of TIMP1, TIMP2, and alpha smooth muscle actin $(\alpha \mathrm{SMA})$ and reverses hepatic fibrosis. By contrast, the HSC-specific ablation of PPAR $\gamma$ aggravates $\mathrm{CCl}_{4}$-induced liver fibrosis and increases $\alpha$ SMA expression [132]. Collectively, these findings clearly link decreased PPAR $\gamma$ activity in HSC to hepatic fibrosis. Accordingly, pioglitazone ameliorates only moderate pericentrilobular fibrosis in rats with no effect on severe bridging fibrosis, which is most likely due to the reduced PPAR $\gamma$ availability for pioglitazone to target under the advanced stages of the disease [178]. On the other hand, the effect of TZDs on fibrosis in humans have been less clear. Unlike in rats, a meta-analysis of TZD effects from eight randomized trials $(n=516)$ on NASH-associated liver fibrosis found pioglitazone to significantly improve fibrosis, particularly in the advanced fibrosis stage with bridging fibrosis and cirrhosis compared to NASH with mild perisinusoidal/periportal fibrosis [179]. This effect could have been independent of PPAR $\gamma$, as TZDs can bind alternative targets such as the mitochondrial pyruvate carrier [179]. In fact, the inhibition of the mitochondrial pyruvate carrier by a next-generation TZD (MSDC0602) was found to reverse hepatic fibrosis in mice, supporting the mitochondria pyruvate carrier as a relevant treatment target $[180,181]$. Nonetheless, the relevance of targeting PPAR $\gamma$ for the treatment of advanced fibrosis in humans remains unclear.

\subsection{RUNX2}

Studies have shown that Runx2 acts as a fibrogenic or tumorigenic transcription factor in hepatic fibrosis or hepatocellular carcinoma [182,183]. Runx2 is expressed in the non-parenchymal cells of the liver but not in the hepatocytes. In a mouse model of NAFLD/NASH, Runx2 becomes upregulated in the HSCs during the development of NAFLD [163].

\section{7. c-Jun}

The impact of c-Jun on fibrogenesis depends on the liver cell type. The deletion of c-Jun only in hepatocytes reduces steatosis but increases fibrosis, whereas its deletion in both hepatocytes and non-parenchymal cells protects against MCD-induced fibrosis in mice [142]. This was linked to reductions in the pro-inflammatory cytokine osteopontin (Opn, also known as SPP1), which is an established marker of a regenerative response called the ductular reaction (DR), which is an essential driver of fibrogenesis. Additional investigations using $\mathrm{Opn}^{-/-}$mice established that c-Jun expression in NPLC promotes NASH-related DR and subsequent fibrosis by upregulating Opn expression [39,184].

\section{Microbiome Dysbiosis}

The contribution of obesity-induced changes in the gut microbiome to the pathogenesis and progression of NAFLD [185] was initially established using germ-free mice and fecal transplant from lean [186] and diet-induced obese mice [187]. Furthermore, the inoculation of germ-free mice with the gut microbiota of obese humans [188] and NASH patients [189] leads to the onset of hepatic steatosis and NASH, respectively. These findings formed the base or microbiota-based therapies for NAFLD such as pre- and probiotics and fecal microbiota transplantation [190-192]. 
The gut microbiota can influence the progression of NAFLD through several pathways, which has been reviewed extensively elsewhere [193]. Briefly, these pathways include changes in gut permeability, low-grade inflammation and immune balance, the modulation of dietary choline and bile acid metabolism, and the production of endogenous substrates [186]. In this review, we highlight that the microbiota, through the production of endogenous substrates, may alter the transcriptional profile of the liver. Major metabolites that are linked to alterations in the gut microbiota include bile acids [194-196], short-chain fatty acids (SCFA) [197] and lipopolysaccharides (LPS) [189]. These metabolites can play an important role in NAFLD progression by mediating the gut-liver axis [198]. Products derived from bile acid metabolism act on FXR to decrease hepatic triglyceride levels and improve glucose metabolism [90]. Specifically, the HFD-induced remodeling of the gut microbiota increases the production of bile salt hydrolase (BSH), which is a bacterial enzyme that hydrolyzes and inactivates tauro- $\beta$-muricholic acid (T- $\beta$-MCA) [199]. T- $\beta$-MCA inhibits intestinal FXR signaling, which suppresses ceramide synthesis [200]. Therefore, microbiome dysbiosis results in increased FXR signaling and ceramide production, which in turn promotes SREBP1c activity and steatosis in the liver [201].

SCFAs have been shown to increase the AMPK activity in liver and muscle tissue [202]. The activation of AMPK triggers PGC- $1 \alpha$ expression, which controls the transcriptional activity of PPAR $\alpha$, PPAR $\gamma$, PPAR $\delta$, LXR, and FXR, which are important transcriptional regulators of cholesterol, lipid, and glucose metabolism [203]. LPS has been shown to activate NF- $\mathrm{kB}$ in cultured hepatocytes [204], which plays a major role in the development of inflammation during NAFLD progression [91] and is highly activated in both mice and patients with NASH. Furthermore, LPS can induce MAP kinase kinase-3 (MKK3) activation, which in turn stimulates $\mathrm{C} / \mathrm{EBP} \beta$ and $\mathrm{C} / \mathrm{EBP} \delta$ binding elements to promote the transcription of CYP2E1 and induce oxidative stress [154].

\section{Prediction of Transcriptional Regulators by Database Analyses}

\subsection{Prognostic Biomarkers for Human NAFLD and NASH}

Many transcriptomic studies have been conducted to elucidate novel biomarkers for the different stages of NAFLD, including steatosis, ballooning, and fibrosis. To elucidate the transcriptional changes that are associated with human NAFLD, we procured publicly available human NAFLD/NASH transcriptome data from the Gene Expression Omnibus (GEO) and subjected them to Ingenuity Pathway Analysis for the prediction of changes in upstream factors (Table 2). Predictions were based on two GEO datasets with strong power analysis (Table 2) as well as a previously published Ingenuity Pathway Analysis (IPA)-based prediction analysis $[7,205,206]$. The activation of PPAR $\gamma$ was the only consistent prediction for simple steatosis, whereas the onset of fibrosis was associated with changes in a larger number of transcription factors, which were consistent in at least half of the datasets. These included the activation of inflammation (NF-kB, RELA, JUN, IRF1, IRF3, STAT1, SP1), glucose production (FOXO1), and lipogenesis (SREBP1), as well as the inhibition of PPAR $\alpha$, PPAR $\gamma$, and RXR $\alpha$. The activation of C/EBP $\beta$, CTNNB1, and SMAD3 and the inhibition of HNF4 $\alpha$ and SMAD7 were also associated with NASH and NASH-induced HCC, suggesting that these factors might contribute to the pathogenesis of advanced stage fibrosis. 
Table 2. Ingenuity Pathway Analysis (IPA) prediction of upstream mechanistic networks that are commonly regulated in the livers of humans and mice with NAFLD.

\begin{tabular}{|c|c|c|c|c|c|c|c|c|c|c|c|c|c|c|c|c|}
\hline \multirow[b]{3}{*}{$\begin{array}{l}\text { Regulation in } \\
\text { Human Fibrosis }\end{array}$} & \multirow[b]{3}{*}{$\begin{array}{c}\text { Transcription } \\
\text { Factor/Regulator }\end{array}$} & \multicolumn{7}{|c|}{ Human } & \multicolumn{8}{|c|}{ Mouse Model } \\
\hline & & \multicolumn{2}{|c|}{ Steatosis } & \multicolumn{4}{|c|}{ Fibrosis } & \multirow{2}{*}{$\begin{array}{c}\text { HCC } \\
\text { g External } \\
\text { IPA HCC } \\
\end{array}$} & \multicolumn{2}{|c|}{ Steatosis } & \multicolumn{6}{|c|}{ NASH } \\
\hline & & $\begin{array}{c}\text { cNon-fibrotic } \\
\text { NAFLD vs. } \\
\text { Healthy } \\
\end{array}$ & $\begin{array}{l}\text { e Steatotic } \\
\text { vs. Healthy }\end{array}$ & $\begin{array}{l}\text { a Fibrotic } \\
\text { vs. } \\
\text { Healthy }\end{array}$ & $\begin{array}{c}\text { bibrotic vs. } \\
\text { Non-Fibrotic } \\
\text { NAFLD }\end{array}$ & $\begin{array}{l}\text { d NASH } \\
\text { vs. } \\
\text { Healthy }\end{array}$ & $\begin{array}{c}{ }^{\mathrm{f}} \text { External } \\
\text { IPA NASH }\end{array}$ & & $\begin{array}{c}\mathrm{h} \\
\mathrm{HFD}\end{array}$ & $\begin{array}{c}\mathrm{i} \\
\mathrm{WD}\end{array}$ & $\begin{array}{c}j \\
M C D\end{array}$ & $\begin{array}{c}\text { kNASH } \\
\text { Diet }\end{array}$ & $\begin{array}{l}{ }^{1} \mathrm{NASH} \\
\mathrm{Diet}_{+} \\
\mathrm{CCl}_{4}\end{array}$ & $\begin{array}{c}\mathrm{n} \\
\mathrm{CCl}_{4}\end{array}$ & $\begin{array}{l}{ }^{\mathrm{m}} \mathrm{WD} \\
+\mathrm{CCl}_{4}\end{array}$ & $\begin{array}{c}\circ \\
\text { STAM }\end{array}$ \\
\hline \multirow{12}{*}{$\begin{array}{c}\text { Consistent } \\
\text { Activation }(2 \geq \\
\text { datasets) }\end{array}$} & FOXO1 * & & & & & & & & & & & & & & & \\
\hline & IRF1* & & & & & & & & & & & & & & & \\
\hline & IRF3 * & & & & & & & & & & & & & & & \\
\hline & $\mathrm{JUN}^{*}$ & & & & & & & & & & & & & & & \\
\hline & $\mathrm{NF}_{\kappa} \mathrm{B}^{*}$ & & & & & & & & & & & & & & & \\
\hline & RELA* & & & & & & & & & & & & & & & \\
\hline & SP1 * & & & & & & & & & & & & & & & \\
\hline & SREBP1* & & & & & & & & & & & & & & & \\
\hline & STAT1* & & & & & & & & & & & & & & & \\
\hline & $\mathrm{C} / \mathrm{EBP} \beta^{+}$ & & & & & & & & & & & & & & & \\
\hline & CTNNB1 $^{+}$ & & & & & & & & & & & & & & & \\
\hline & SMAD3 $^{+}$ & & & & & & & & & & & & & & & \\
\hline \multirow{11}{*}{$\begin{array}{c}\text { Activation (1 } \\
\text { dataset) }\end{array}$} & CREB & & & & & & & & & & & & & & & \\
\hline & EGR1 & & & & & & & & & & & & & & & \\
\hline & ESR2 & & & & & & & & & & & & & & & \\
\hline & IRF7 & & & & & & & & & & & & & & & \\
\hline & LXR & & & & & & & & & & & & & & & \\
\hline & NFAT & & & & & & & & & & & & & & & \\
\hline & NRF2 & & & & & & & & & & & & & & & \\
\hline & RAR $\alpha$ & & & & & & & & & & & & & & & \\
\hline & RUNX2 & & & & & & & & & & & & & & & \\
\hline & SPI1 & & & & & & & & & & & & & & & \\
\hline & STAT2 & & & & & & & & & & & & & & & \\
\hline
\end{tabular}


Table 2. Cont.

\begin{tabular}{|c|c|c|c|c|c|c|c|c|c|c|c|c|c|c|c|c|}
\hline \multirow[b]{3}{*}{$\begin{array}{l}\text { Regulation in } \\
\text { Human Fibrosis }\end{array}$} & \multirow[b]{3}{*}{$\begin{array}{l}\text { Transcription } \\
\text { Factor/Regulator }\end{array}$} & \multicolumn{7}{|c|}{ Human } & \multicolumn{8}{|c|}{ Mouse Model } \\
\hline & & \multicolumn{2}{|c|}{ Steatosis } & \multicolumn{4}{|c|}{ Fibrosis } & \multirow{2}{*}{$\begin{array}{c}\text { HCC } \\
\text { g External } \\
\text { IPA HCC }\end{array}$} & \multicolumn{2}{|c|}{ Steatosis } & \multicolumn{6}{|c|}{ NASH } \\
\hline & & $\begin{array}{c}\text { c Non-fibrotic } \\
\text { NAFLD vs. } \\
\text { Healthy }\end{array}$ & $\begin{array}{l}\text { e Steatotic } \\
\text { vs. Healthy }\end{array}$ & $\begin{array}{c}\text { a Fibrotic } \\
\text { vs. } \\
\text { Healthy }\end{array}$ & $\begin{array}{c}\text { b Fibrotic vs. } \\
\text { Non-Fibrotic } \\
\text { NAFLD }\end{array}$ & $\begin{array}{l}\text { d NASH } \\
\text { vs. } \\
\text { Healthy }\end{array}$ & $\begin{array}{l}{ }^{\mathrm{f}} \text { External } \\
\text { IPA NASH }\end{array}$ & & $\begin{array}{c}\mathrm{h} \\
\mathrm{HFD}\end{array}$ & $\begin{array}{c}\mathrm{i} \\
\mathrm{WD}\end{array}$ & $\begin{array}{c}j \\
M C D\end{array}$ & $\begin{array}{c}\text { kNASH } \\
\text { Diet }\end{array}$ & $\begin{array}{l}{ }^{1} \text { NASH } \\
\text { Diet + } \\
\mathrm{CCl}_{4}\end{array}$ & $\begin{array}{c}\mathrm{n} \\
\mathrm{CCl}_{4}\end{array}$ & $\begin{array}{l}\mathrm{m} \text { WD } \\
+{ }_{+} \mathrm{CCl}_{4}\end{array}$ & $\begin{array}{c}\circ \\
\text { STAM }\end{array}$ \\
\hline \multirow{5}{*}{$\begin{array}{c}\text { Consistent } \\
\text { Inhibition (2 } \geq \\
\text { datasets) }\end{array}$} & PPAR $\alpha^{*}$ & & & & & & & & & & & & & & & \\
\hline & PPAR $\gamma^{*}$ & & & & & & & & & & & & & & & \\
\hline & $\mathrm{RXR} \alpha^{*}$ & & & & & & & & & & & & & & & \\
\hline & HNF4 $\alpha^{+}$ & & & & & & & & & & & & & & & \\
\hline & SMAD7 $^{+}$ & & & & & & & & & & & & & & & \\
\hline \multirow{9}{*}{$\begin{array}{c}\text { Inhibition (1 } \\
\text { dataset) }\end{array}$} & AHR & & & & & & & & & & & & & & & \\
\hline & HDAC1 & & & & & & & & & & & & & & & \\
\hline & HNF1 $\alpha$ & & & & & & & & & & & & & & & \\
\hline & NR1h & & & & & & & & & & & & & & & \\
\hline & NR3C1 & & & & & & & & & & & & & & & \\
\hline & NR5A2 & & & & & & & & & & & & & & & \\
\hline & RBL1 & & & & & & & & & & & & & & & \\
\hline & STAT5a & & & & & & & & & & & & & & & \\
\hline & THR $\beta$ & & & & & & & & & & & & & & & \\
\hline \multirow{5}{*}{$\begin{array}{l}\text { Inconsistent } \\
\text { Regulation }\end{array}$} & STAT3 & & & & & & & & & & & & & & & \\
\hline & MYC & & & & & & & & & & & & & & & \\
\hline & p53 & & & & & & & & & & & & & & & \\
\hline & IRF8 & & & & & & & & & & & & & & & \\
\hline & ESR1 & & & & & & & & & & & & & & & \\
\hline
\end{tabular}

Human GEO Accession GSE130970 was divided into three independent IPA comparative analyses: ${ }^{\mathrm{a}}$ Advanced fibrotic (fibrosis score $\left.>3, n=16\right)$ versus healthy $(n=8)$, ${ }^{\mathrm{b}}$ Fibrotic versus non-fibrotic NAFLD (NAS $>3, n=11$ ), and ${ }^{c}$ non-fibrotic NAFLD versus healthy. Human GEO Accession GSE89632 was similarly analyzed in three independent analyses comparing transcriptomic changes among human livers with ${ }^{\mathrm{d}}$ NASH $(n=19)$ vs. healthy $(n=24)$, NASH vs. simple steatosis $(n=20)$ and ${ }^{\mathrm{e}}$ simple steatosis vs. healthy. The conclusions of a previously published upstream regulators analysis for ${ }^{\mathrm{f}}$ NASH and ${ }^{\mathrm{g}}$ NASH-associated HCC are included as well. The mouse models of steatosis using ${ }^{\mathrm{h}}$ HFD (GSE93132) and ${ }^{\mathrm{i}}$ Western

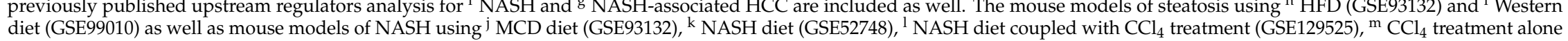

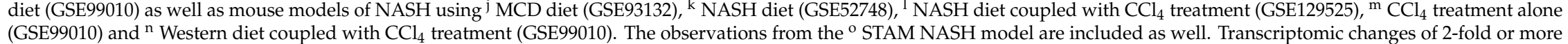
(GSE99010) and ${ }^{\mathrm{n}}$ Western diet coupled with $\mathrm{CCl}_{4}$ treatment (GSE99010). The observations from the ${ }^{\mathrm{o}}$ STAM NASH model are included as well. Transcriptomic changes of 2-fold or more
were included in the IPA. The table includes the mechanistic network of the transcription factors with a prediction $\mathrm{Z}$ score of greater than 2 for activation (red) or less than -2 for inhibition (blue). Datasets for mouse hepatocellular carcinoma (HCC) models using extended $\mathrm{CCl}_{4}$ treatment for 24 weeks were excluded from the IPA prediction. The analysis of human livers with NASH vs. simple steatosis from GSE89632 dataset did not yield any prediction for significant changes in upstream activity and was excluded from the table. Abbreviations: forkhead protein $\mathrm{O}$ (FoxO), interferon regulatory factor (IRF), nuclear factor of the $\mathrm{k}$ light chain enhancer of $\mathrm{B}$ cells (NF- $\mathrm{k}$ ), $\mathrm{v}$-rel avian reticuloendotheliosis viral oncogene homolog $\mathrm{A}$ (RELA), Specific Protein 1 (SP1), sterol regulatory element binding protein (SREBP), signal transducer and activator of transcription (STAT), CCAAT/enhancer binding protein (C/EBP), Catenin Beta (ESR), liver X receptor (LXR), nuclear factor of activated T-cells (NFAT), nuclear factor * ${ }^{*}$ Consistent regulation in 2 or more human NASH datasets. ${ }^{\dagger}$ Consistent regulation in human NASH and HCC. 


\subsection{Altered Transcription Factors in Mouse Models of NAFLD and NASH}

The same strategy was applied to predict the changes in the activity of transcription factors in mouse models of NAFLD/NASH. We performed IPA upstream activity prediction analysis for publicly available liver transcriptome data from mouse models of steatosis that were established by feeding high caloric diets $[18,207]$ as well as mouse models of NASH that were established by feeding an MCD diet [207], NASH diet, or a combination of high caloric diets coupled with $\mathrm{CCl}_{4}$ treatment $[18,208]$. Additionally, we included the observations of a previously published STZ-induced NASH and HCC model (STAM) [7]. Transgenic mouse models that involve genetic manipulations were excluded, since our comparative analysis was not aimed at delineating the transcriptional consequences of rare gene variants in humans and mice. As anticipated, the activation of most consistent pathways in humans (Table 2) were also confirmed in most mouse models. However, in contrast to the downregulation of PPAR $\alpha, \operatorname{PPAR} \gamma$, and RXR $\alpha$ in human livers with NASH, these pathways were upregulated in most mouse models of NASH (Table 2). The activity regulation of PPAR $\alpha, \operatorname{PPAR} \gamma$, and RXR $\alpha$ in mouse models of NASH was instead more representative of their activity in human livers with simple steatosis (Table 2).

IPA analysis of the mouse models also identified pathways that were not predicted to be affected among human NASH datasets. Among these, the activation of SMAD2, SMAD4, YAP1, NOTCH1, EP300, p63, and the inhibition of nuclear receptor corepressor (NCOR) has been previously linked to human NASH by independent studies (Table 3) [42,166,173,209-212]. Therefore, most mouse models mimic the transcriptional signature of human NASH for these transcription factors. However, the consistent inhibition of SREBP2 and the activation of fos proto-oncogene (FOS) and PGC1 $\alpha$ in mouse NASH models mimicked human steatosis but were absent in the setting of human fibrosis (Table 3) $[102,213,214]$. Furthermore, increased FOS mRNA in fibrotic versus non-fibrotic NAFLD patients was in line with increased EGR1 activity, which promotes FOS expression, as previously published (Table 2). However, IPA did not predict FOS activation, as this would be anticipated to inhibit NF- $\mathrm{KB}$ and SP1 and activate CEBBP, which was in contrast with the regulation in fibrotic livers (Table 2). Other frequently altered transcriptional mechanisms in mouse NASH models, which were not previously associated with human NASH, included PPAR $\delta$, HIF1 $\alpha$, MED1, NCOA1, NCOA2, SMARCA4, FOXO3, HDAC2, STAT5b, and STAT6 (Table 4). Individual transcriptomic datasets from mouse livers also predicted the regulation of unique pathways for each dataset, which were not predicted to be regulated in other mouse models (Table 4). Since IPA prediction of upstream factors in human NASH also failed to identify changes in the activity of these sets of transcription factors in Tables 3 and 4, studying their relevance in the pathogenesis of NASH in humans would be beneficial prior to investigating their roles in pre-clinical rodent models of NASH. It is worth mentioning that the activation of ChREBP and C/EBP $\alpha$ were only confirmed in the mouse models using MCD and WD coupled with $\mathrm{CCl}_{4}$, respectively, but they were not detected in human fibrosis datasets. Another category of altered transcription factors belonged to those that were altered in a single human dataset but not in any of the mouse models (Table 5). Although the activity regulation of these factors could be relevant in the pathogenesis of NASH, corroborating evidence is lacking.

To determine how the transcriptional activity of popular NASH mouse models faired against human NASH, we implemented a scoring strategy ranging from +2 to -2 for each transcription factor: +2 for the confirmation of a transcriptional activity in a mouse model, which was observed in more than one human NASH dataset (i.e., NF- $\mathrm{kB}$ ); -2 for the reversal of a transcriptional activity, which was observed in more than one human NASH dataset (i.e., PPAR $\gamma$ ) $;+1$ for the confirmation of a transcriptional activity, which was observed only in one human NASH dataset (i.e., SMAD7); -1 for the reversal of a transcriptional activity, which was observed only in one human NASH dataset (i.e., THR $\beta$ for $\mathrm{CCl}_{4}$ model); -1 when multiple confirmations for a transcriptional activity among human datasets remained unchanged in a mouse model (i.e., NF- $\mathrm{kB}$ for $\mathrm{NASH}$ diet $+\mathrm{CCl}_{4}$ model); 0 for a lack of transcriptional activity in a mouse model, which was also observed in some of the human NASH datasets (i.e., $\mathrm{THRb}$ for all models except $\mathrm{CCl}_{4}$ ); and 0 when a transcriptional activity was predicted 
to be inconsistently regulated among different human NASH datasets regardless of the state of the activity of that transcription factor within the mouse models (i.e., STAT3). From a possible maximum score of +47 for all the common transcription factors (Table 2), the NASH diet, MCD diet, NASH diet + $\mathrm{CCl}_{4}, \mathrm{CCl}_{4}$ alone, and $\mathrm{WD}+\mathrm{CCl}_{4}$ netted total scores of 23, 27,-10, 12 and 7 , respectively, suggesting that the NASH diet and MCD diet exhibit transcriptional activity profiles that are more representative of human $\mathrm{NASH}$, whereas the models that involved $\mathrm{CCl}_{4}$ treatment did not. We excluded the STAM mouse model due to the low number of predicted matches.

Table 3. IPA prediction of upstream regulators that were detected in the livers of mouse models of NASH but not in human NASH cohorts.

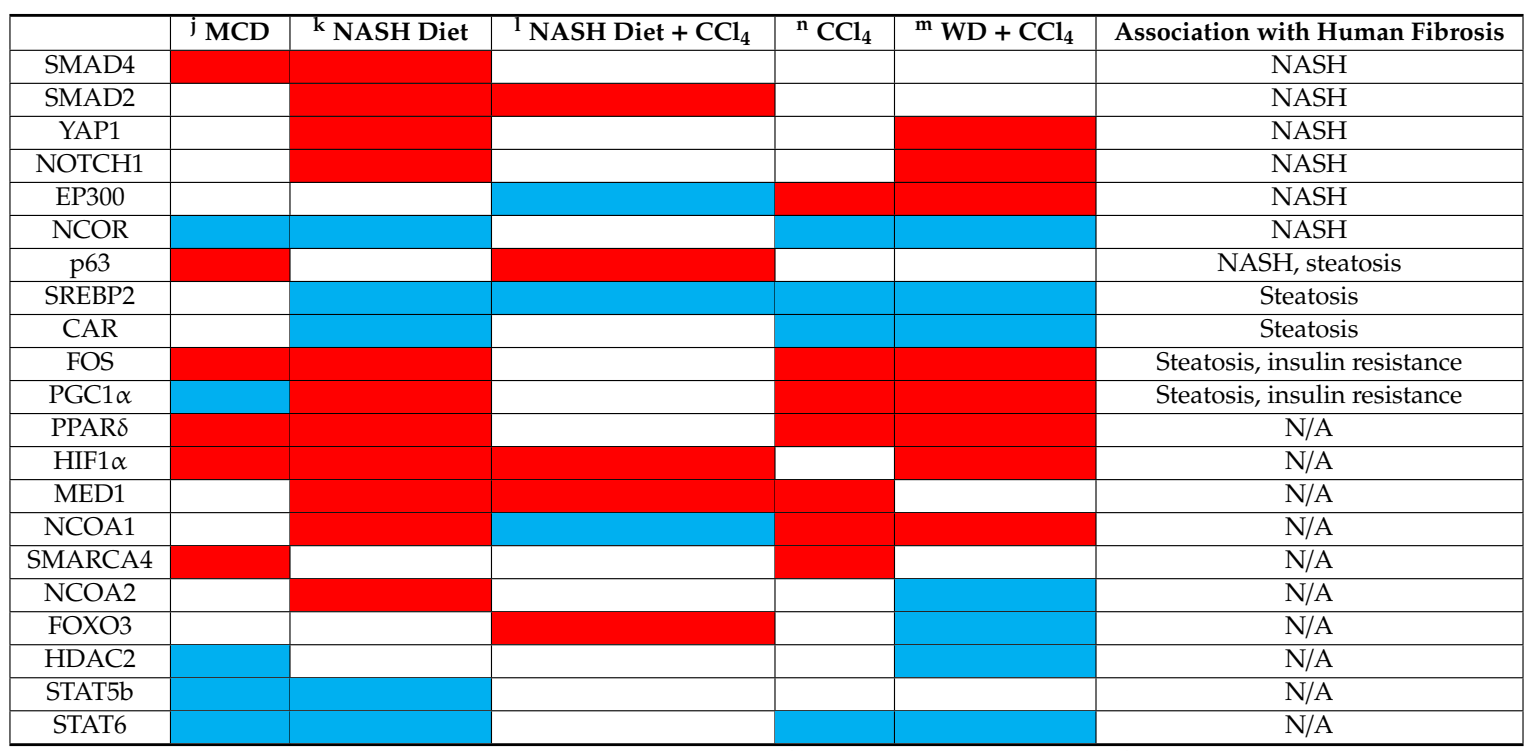

Mouse models of NASH using ${ }^{j}$ MCD diet (GSE93132), ${ }^{k}$ NASH diet (GSE52748), ${ }^{1}$ NASH diet coupled with $\mathrm{CCl}_{4}$ treatment (GSE129525), ${ }^{\mathrm{m}} \mathrm{CCl}_{4}$ treatment alone (GSE99010) and ${ }^{\mathrm{n}}$ Western diet coupled with $\mathrm{CCl}_{4}$ treatment (GSE99010). Abbreviations: transcription factors against decapentaplegic homolog (SMAD), yes-associated protein (YAP), notch receptor 1 (NOTCH1), Histone Acetyltransferase P300 (EP300), nuclear receptor corepressor (NCOR), sterol regulatory element binding protein (SREBP), constitutive androstane receptor (CAR), fos proto-oncogene (FOS), PPAR $\gamma$ coactivator 1 alpha (PGC1 $\alpha$ ), peroxisome proliferator-activated receptor (PPAR), hypoxia inducible factor $1 \alpha(\mathrm{HIF} 1 \alpha)$, mediator complex subunit 1 (MED1), nuclear receptor coactivator (NCOA), SWI/SNF related, matrix associated, actin dependent regulator of chromatin subfamily A member 4 (SMARCA4), forkhead protein O (FoxO), histone deacetylase (HDAC), signal transducer and activator of transcription (STAT). 
Table 4. IPA prediction of upstream mechanistic networks that are unique to each mouse model.

\begin{tabular}{|c|l|l|l|l|l|}
\hline & ${ }^{\mathbf{j}} \mathbf{M C D}$ & ${ }^{k}$ NASH Diet & ${ }^{1} \mathbf{N A S H}$ Diet $+\mathbf{C C l}_{4}$ & ${ }^{\mathbf{n}} \mathbf{C C l}_{4}$ & ${ }^{\mathbf{m}} \mathbf{W D}+\mathbf{C C l}_{\mathbf{4}}$ \\
\hline ARNTL & & & & & \\
\hline CDKN2A & & & & & \\
\hline C/EBP $\alpha$ & & & & & \\
\hline ChREBP & & & & & \\
\hline CIITA & & & & & \\
\hline E2F & & & & & \\
\hline FOXO4 & & & & & \\
\hline HNF1 $\alpha$ & & & & & \\
\hline HSF1 & & & & & \\
\hline IRF9 & & & & & \\
\hline KLF4 & & & & & \\
\hline MAX & & & & & \\
\hline MYB & & & & & \\
\hline PGR & & & & & \\
\hline RARB & & & & & \\
\hline RB1 & & & & & \\
\hline RORA & & & & & \\
\hline SNAI & & & & & \\
\hline SP3 & & & & & \\
\hline STAT4 & & & & & \\
\hline TCF7L2 & & & & & \\
\hline THR $\alpha$ & & & & & \\
\hline VDR & & & & & \\
\hline WT1 & & & & & \\
\hline YNF1 & & & & & \\
\hline
\end{tabular}

Mouse models of NASH using ${ }^{\mathrm{j}} \mathrm{MCD} \operatorname{diet}(\mathrm{GSE} 93132),{ }^{\mathrm{k}} \mathrm{NASH} \operatorname{diet}\left(\mathrm{GSE52748)},{ }^{1} \mathrm{NASH}\right.$ diet coupled with $\mathrm{CCl}_{4}$ treatment (GSE129525), ${ }^{\mathrm{m}} \mathrm{CCl}_{4}$ treatment alone (GSE99010) and ${ }^{\mathrm{n}}$ Western diet coupled with $\mathrm{CCl}_{4}$ treatment (GSE99010). Abbreviations: androgen receptor (AR), aryl hydrocarbon receptor nuclear translocator like (ARNTL), cyclin dependent kinase inhibitor 2A (CDKN2A), CCAAT/enhancer binding protein (C/EBP), class ii major histocompatibility complex transactivator (CIITA), forkhead protein $\mathrm{O}$ (FoxO), hepatocyte nuclear factor (HNF), heat shock transcription factor 1 (HSF1), interferon regulatory factor (IRF), kruppel like factor 4 (KLF4), MYC associated factor X (MAX), myb proto-oncogene (MYB), progesterone receptor (PGR), retinoic acid receptor beta (RARB), retinoblastoma transcriptional corepressor 1 (RB1), retinoic acid receptor-related orphan receptor alpha (RORA), snail family transcriptional repressor (SNAI), specificity protein 3 (SP3), signal transducer and activator of transcription (STAT), transcription factor 7 like 2 (TCF7L2), thyroid hormone receptor $\alpha$ (THR $\alpha$ ), vitamin D receptor (VDR), Wilms' tumor protein (WT1), Y box-binding protein 1 (Ybx1), IKAROS family zinc finger 1 (ZNFn1a1).

Table 5. IPA prediction of upstream mechanistic networks that are unique to each human NASH cohort.

\begin{tabular}{|c|l|c|l|l|}
\hline & ${ }^{\text {a }}$ Fibrotic vs. Healthy & $\begin{array}{c}\text { b Fibrotic vs. } \\
\text { Non-Fibrotic NAFLD }\end{array}$ & d NASH vs. Healthy & ${ }^{\mathbf{f}}$ External IPA NASH \\
\hline CCND1 & & & & \\
\hline CCNE1 & & & & \\
\hline HMGB1 & & & & \\
\hline IRF2 & & & & \\
\hline IRF5 & & & & \\
\hline KLF2 & & & & \\
\hline NRIP1 & SOX2 & & & \\
\hline
\end{tabular}

Human GEO Accession GSE130970 was divided into three independent IPA comparative analyses: ${ }^{\text {a }}$ Advanced fibrotic (fibrosis score $>3, n=16$ ) versus healthy $(n=8),{ }^{b}$ Fibrotic versus non-fibrotic NAFLD (NAS $>3, n=11$ ), and ${ }^{\mathrm{d}}$ non-fibrotic NAFLD versus healthy. ${ }^{\mathrm{f}}$ Previously reported IPA of NASH (Kakehashi et al.). Abbreviations: cyclin D1 (CCND1), cyclin E1 (CCNE1), high mobility group box 1 (HMGB1), interferon regulatory factor (IRF), kruppel like factor 2 (KLF2), nuclear receptor interacting protein 1 (NRIP1), sex determining region Y box transcription factor 2 (SOX2). 


\section{Conclusions}

Maladaptive responses to obesity results in the activation of inflammatory and fibrogenic pathways in the liver. Here, we reviewed the transcription factors, the activity of which have been commonly associated with obesity-induced NAFLD and NASH. The development of NAFLD and NASH strongly correlates with the dysregulation of transcriptional regulators that play a role in lipid metabolism, inflammation, metabolic stress, and fibrosis. Interestingly, the review of gluconeogenic transcription factors indicated a protective function against steatosis and NASH, since their loss often resulted in disease. The field of main regulators will continue to increase with heightened focus on delineating new pathways in the pathogenesis of NAFLD, as each of the areas discussed in this review are still being actively researched and adding to our understanding of the transcriptional regulation of NAFLD.

Our review also indicates that none of the diet-based rodent models replicate all the features of the human pathophysiology. Our observations suggested that the FCP diet and MCD diet exhibit transcriptional activity profiles that are more representative of human NASH, whereas the models that involved chemical induction, such as $\mathrm{CCl}_{4}$ treatment, did not. The generation of novel experimental models that more accurately reproduce human pathophysiology, including mice with humanized livers [215], will be central to the discovery of tractable targets for the management of NAFLD.

Author Contributions: Conceptualized the outline of the review: S.S.; performed literature search: S.S., J.Q. and B.A.E.; wrote and edited the manuscript: S.S., J.Q. and B.A.E.; conceptualized the outline: B.A.E., directed and validated the review: B.A.E.; analyzed publicly available datasets: B.A.E. All authors have read and agreed to the published version of the manuscript.

Funding: This review article did not receive any external funding.

Conflicts of Interest: The authors declare no conflict of interest.

\section{References}

1. Machado, M.V.; Cortez-Pinto, H. Non-alcoholic fatty liver disease: What the clinician needs to know. World J. Gastroenterol. 2014, 20, 12956-12980. [CrossRef] [PubMed]

2. Younossi, Z.; Anstee, Q.M.; Marietti, M.; Hardy, T.; Henry, L.; Eslam, M.; George, J.; Bugianesi, E. Global burden of NAFLD and NASH: Trends, predictions, risk factors and prevention. Nat. Rev. Gastroenterol. Hepatol. 2017, 15, 11-20. [CrossRef]

3. Iwaisako, K.; Brenner, D.A.; Kisseleva, T. What's new in liver fibrosis? The origin of myofibroblasts in liver fibrosis. J. Gastroenterol. Hepatol. 2012, 27, 65-68. [CrossRef] [PubMed]

4. Benedict, M.; Zhang, X. Non-alcoholic fatty liver disease: An expanded review. World J. Hepatol. 2017, 9, 715-732. [CrossRef] [PubMed]

5. Oseini, A.M.; Sanyal, A.J. Therapies in non-alcoholic steatohepatitis (NASH). Liver Int. 2017, 37, 97-103. [CrossRef] [PubMed]

6. Paschos, P.; Paletas, K. Non alcoholic fatty liver disease and metabolic syndrome. Hippokratia 2009, 13, 9-19.

7. Kakehashi, A.; Stefanov, V.E.; Ishii, N.; Okuno, T.; Fujii, H.; Kawai, K.; Kawada, N.; Wanibuchi, H. Proteome Characteristics of Non-Alcoholic Steatohepatitis Liver Tissue and Associated Hepatocellular Carcinomas. Int. J. Mol. Sci. 2017, 18, 434. [CrossRef]

8. Buzzetti, E.; Pinzani, M.; Tsochatzis, E.A. The multiple-hit pathogenesis of non-alcoholic fatty liver disease (NAFLD). Metabolism 2016, 65, 1038-1048. [CrossRef]

9. Zaret, K.S.; Carroll, J.S. Pioneer transcription factors: Establishing competence for gene expression. Genes Dev. 2011, 25, 2227-2241. [CrossRef]

10. Shiri-Sverdlov, R.; Wouters, K.A.M.; Van Gorp, P.; Gijbels, M.J.; Noël, B.; Buffat, L.; Staels, B.; Maeda, N.; Van Bilsen, M.; Hofker, M.H. Early diet-induced non-alcoholic steatohepatitis in APOE2 knock-in mice and its prevention by fibrates. J. Hepatol. 2006, 44, 732-741. [CrossRef]

11. Horie, Y.; Suzuki, A.; Kataoka, E.; Sasaki, T.; Hamada, K.; Sasaki, J.; Mizuno, K.; Hasegawa, G.; Kishimoto, H.; Iizuka, M.; et al. Hepatocyte-specific Pten deficiency results in steatohepatitis and hepatocellular carcinomas. J. Clin. Investig. 2004, 113, 1774-1783. [CrossRef] [PubMed] 
12. Nakagawa, H.; Umemura, A.; Taniguchi, K.; Font-Burgada, J.; Dhar, D.; Ogata, H.; Zhong, Z.; Valasek, M.A.; Seki, E.; Hidalgo, J.; et al. ER stress cooperates with hypernutrition to trigger TNF-dependent spontaneous HCC development. Cancer Cell 2014, 26, 331-343. [CrossRef] [PubMed]

13. Ito, M.; Suzuki, J.; Tsujioka, S.; Sasaki, M.; Gomori, A.; Shirakura, T.; Hirose, H.; Ito, M.; Ishihara, A.; Iwaasa, H.; et al. Longitudinal analysis of murine steatohepatitis model induced by chronic exposure to high-fat diet. Hepatol. Res. 2007, 37, 50-57. [CrossRef] [PubMed]

14. Stephenson, K.; Kennedy, L.; Hargrove, L.; Demieville, J.; Thomson, J.; Alpini, G.; Francis, H.L. Updates on Dietary Models of Nonalcoholic Fatty Liver Disease: Current Studies and Insights. Gene Expr. 2018, 18, 5-17. [CrossRef]

15. Nakae, D.; Mizumoto, Y.; Andoh, N.; Tamura, K.; Horiguchi, K.; Endoh, T.; Kobayashi, E.; Tsujiuchi, T.; Denda, A.; Lombardi, B.; et al. Comparative Changes in the Liver of Female Fischer-344 Rats after Short-Term Feeding of a Semipurified or a Semisynthetic L-Amino Acid-Defined Choline-Deficient Diet. Toxicol. Pathol. 1995, 23, 583-590. [CrossRef]

16. Mamikutty, N.; Thent, Z.; Suhaimi, F. Fructose-Drinking Water Induced Nonalcoholic Fatty Liver Disease and Ultrastructural Alteration of Hepatocyte Mitochondria in Male Wistar Rat. BioMed Res. Int. 2015, 2015, 1-7. [CrossRef]

17. Fujii, M.; Shibazaki, Y.; Wakamatsu, K.; Honda, Y.; Kawauchi, Y.; Suzuki, K.; Arumugam, S.; Watanabe, K.; Ichida, T.; Asakura, H.; et al. A murine model for non-alcoholic steatohepatitis showing evidence of association between diabetes and hepatocellular carcinoma. Med. Mol. Morphol. 2013, 46, 141-152. [CrossRef]

18. Tsuchida, T.; Lee, Y.A.; Fujiwara, N.; Ybanez, M.; Allen, B.; Martins, S.; Fiel, M.I.; Goossens, N.; Chou, H.-I.; Hoshida, Y.; et al. A simple diet- and chemical-induced murine NASH model with rapid progression of steatohepatitis, fibrosis and liver cancer. J. Hepatol. 2018, 69, 385-395. [CrossRef]

19. Sinton, M.; Hay, D.C.; Drake, A.J. Metabolic control of gene transcription in non-alcoholic fatty liver disease: The role of the epigenome. Clin. Epigenet. 2019, 11, 104. [CrossRef]

20. Montagner, A.; Polizzi, A.; Fouché, E.; Ducheix, S.; Lippi, Y.; Lasserre, F.; Barquissau, V.; Régnier, M.; Lukowicz, C.; Benhamed, F.; et al. Liver PPAR $\alpha$ is crucial for whole-body fatty acid homeostasis and is protective against NAFLD. Gut 2016, 65, 1202-1214. [CrossRef]

21. Ponugoti, B.; Kemper, J.K.; Fang, S. Functional Interaction of Hepatic Nuclear Factor-4 and Peroxisome Proliferator-Activated Receptor- Gamma Coactivator 1 alpha in CYP7A1 Regulation Is Inhibited by a Key Lipogenic Activator, Sterol Regulatory Element-Binding Protein-1c. Mol. Endocrinol. 2007, 21, 2698-2712. [CrossRef] [PubMed]

22. Benhamed, F.; Denechaud, P.-D.; Lemoine, M.; Robichon, C.; Moldes, M.; Bertrand-Michel, J.; Ratziu, V.; Serfaty, L.; Housset, C.; Capeau, J.; et al. The lipogenic transcription factor ChREBP dissociates hepatic steatosis from insulin resistance in mice and humans. J. Clin. Investig. 2012, 122, 2176-2194. [CrossRef] [PubMed]

23. Tanaka, N.; Aoyama, T.; Kimura, S.; Gonzalez, F.J. Targeting nuclear receptors for the treatment of fatty liver disease. Pharmacol. Ther. 2017, 179, 142-157. [CrossRef] [PubMed]

24. Ahn, S.B.; Jang, K.; Jun, D.W.; Lee, B.H.; Shin, K.J. Expression of Liver X Receptor Correlates with Intrahepatic Inflammation and Fibrosis in Patients with Nonalcoholic Fatty Liver Disease. Dig. Dis. Sci. 2014, 59, $2975-2982$. [CrossRef] [PubMed]

25. Baciu, C.; Pasini, E.; Angeli, M.; Schwenger, K.; Afrin, J.; Humar, A.; Fischer, S.; Patel, K.; Allard, J.; Bhat, M. Systematic integrative analysis of gene expression identifies HNF4A as the central gene in pathogenesis of non-alcoholic steatohepatitis. PLoS ONE 2017, 12, e0189223. [CrossRef]

26. Kaltenecker, D.; Themanns, M.; Mueller, K.M.; Spirk, K.; Suske, T.; Merkel, O.; Kenner, L.; Luís, A.; Kozlov, A.; Haybaeck, J.; et al. Hepatic growth hormone-JAK2-STAT5 signalling: Metabolic function, non-alcoholic fatty liver disease and hepatocellular carcinoma progression. Cytokine 2019, 124, 154569. [CrossRef]

27. Rahman, S.M.; Janssen, R.C.; Jiang, H.; Qadri, I.; MacLean, K.N.; Friedman, J.E.; Schroeder-Gloeckler, J.M. CCAAT/enhancing binding protein $\beta$ deletion in mice attenuates inflammation, endoplasmic reticulum stress, and lipid accumulation in diet-induced nonalcoholic steatohepatitis. Hepatology 2007, 45, 1108-1117. [CrossRef]

28. Piccinin, E.; Villani, G.; Moschetta, A. Metabolic aspects in NAFLD, NASH and hepatocellular carcinoma: The role of PGC1 coactivators. Nat. Rev. Gastroenterol. Hepatol. 2018, 16, 160-174. [CrossRef] 
29. Valenti, L.; Rametta, R.; Dongiovanni, P.; Maggioni, M.; Fracanzani, A.L.; Zappa, M.; Lattuada, E.; Roviaro, G.; Fargion, S. Increased Expression and Activity of the Transcription Factor FOXO1 in Nonalcoholic Steatohepatitis. Diabetes 2008, 57, 1355-1362. [CrossRef]

30. Videla, L.; Tapia, G.; Rodrigo, R.; Pettinelli, P.; Haim, D.; Santibáñez, C.; Araya, A.V.; Smok, G.; Csendes, A.; Gutiérrez, L.; et al. Liver NF-kB and AP-1 DNA Binding in Obese Patients. Obesity 2009, 17, 973-979. [CrossRef]

31. Severa, M.; Islam, S.A.; Waggoner, S.N.; Jiang, Z.; Kim, N.D.; Ryan, G.; Kurt-Jones, E.; Charo, I.; Caffrey, D.R.; Boyartchuk, V.L.; et al. The transcriptional repressor BLIMP1 curbs host defenses by suppressing expression of the chemokine CCL8. J. Immunol. 2014, 192, 2291-2304. [CrossRef] [PubMed]

32. Grohmann, M.; Wiede, F.; Dodd, G.T.; Gurzov, E.N.; Ooi, G.J.; Butt, T.; Rasmiena, A.A.; Kaur, S.; Gulati, T.; Goh, P.K.; et al. Obesity Drives STAT-1-Dependent NASH and STAT-3-Dependent HCC. Cell 2018, 175, 1289.e20-1306.e20. [CrossRef] [PubMed]

33. Dorn, C.; Engelmann, J.C.; Saugspier, M.; Koch, A.; Hartmann, A.; Müller-Nurasyid, M.; Spang, R.; Bosserhoff, A.K.; Hellerbrand, C. Increased expression of c-Jun in nonalcoholic fatty liver disease. Lab. Investig. 2014, 94, 394-408. [CrossRef] [PubMed]

34. Zou, A.; Magee, N.; Deng, F.; Lehn, S.; Zhong, C.; Zhang, Y. Hepatocyte nuclear receptor SHP suppresses inflammation and fibrosis in a mouse model of nonalcoholic steatohepatitis. J. Biol. Chem. 2018, 293, 8656-8671. [CrossRef]

35. Shimozono, R.; Asaoka, Y.; Yoshizawa, Y.; Aoki, T.; Noda, H.; Yamada, M.; Kaino, M.; Mochizuki, H. Nrf2 Activators Attenuate the Progression of Nonalcoholic Steatohepatitis-Related Fibrosis in a Dietary Rat Model. Mol. Pharmacol. 2013, 84, 62-70. [CrossRef]

36. Zhong, L.; Huang, L.; Xue, Q.; Liu, C.; Xu, K.; Shen, W.; Deng, L. Cell-specific elevation of Runx2 promotes hepatic infiltration of macrophages by upregulating MCP-1 in high-fat diet-induced mice NAFLD. J. Cell. Biochem. 2019, 120, 11761-11774. [CrossRef]

37. Lebeaupin, C.; Vallee, D.; Rousseau, D.; Patouraux, S.; Bonnafous, S.; Adam, G.; Luciano, F.; Luci, C.; Anty, R.; Iannelli, A.; et al. Bax inhibitor-1 protects from nonalcoholic steatohepatitis by limiting inositol-requiring enzyme 1 alpha signaling in mice. Hepatology 2018, 68, 515-532. [CrossRef]

38. Lee, A.-H.; Scapa, E.F.; Cohen, D.E.; Glimcher, L.H. Regulation of Hepatic Lipogenesis by the Transcription Factor XBP1. Science 2008, 320, 1492-1496. [CrossRef]

39. Cazanave, S.; Podtelezhnikov, A.; Jensen, K.; Seneshaw, M.; Kumar, D.P.; Min, H.-K.; Santhekadur, P.K.; Banini, B.; Mauro, A.G.; Oseini, A.M.; et al. The Transcriptomic Signature of Disease Development and Progression of Nonalcoholic Fatty Liver Disease. Sci. Rep. 2017, 7, 17193. [CrossRef]

40. Gonzalez-Rodriguez, A.; Mayoral, R.; Agra, N.; Valdecantos, M.P.; Pardo, V.; E Miquilena-Colina, M.; Vargas-Castrillón, J.; Iacono, O.L.; Corazzari, M.; Fimia, G.M.; et al. Impaired autophagic flux is associated with increased endoplasmic reticulum stress during the development of NAFLD. Cell Death Dis. 2014, 5, e1179. [CrossRef]

41. Lee, S.; Kim, S.; Hwang, S.; Cherrington, N.J.; Ryu, D.-Y. Dysregulated expression of proteins associated with ER stress, autophagy and apoptosis in tissues from nonalcoholic fatty liver disease. Oncotarget 2017, 8, 63370-63381. [CrossRef] [PubMed]

42. Dattaroy, D.; Pourhoseini, S.; Das, S.; Alhasson, F.; Seth, R.; Nagarkatti, M.; Michelotti, G.A.; Diehl, A.M.; Chatterjee, S. Micro-RNA 21 inhibition of SMAD7 enhances fibrogenesis via leptin-mediated NADPH oxidase in experimental and human nonalcoholic steatohepatitis. Am. J. Physiol. Liver Physiol. 2014, 308, G298-G312. [CrossRef] [PubMed]

43. Teratani, T.; Tomita, K.; Suzuki, T.; Furuhashi, H.; Irie, R.; Nishikawa, M.; Yamamoto, J.; Hibi, T.; Miura, S.; Minamino, T.; et al. Aortic carboxypeptidase-like protein, a WNT ligand, exacerbates nonalcoholic steatohepatitis. J. Clin. Investig. 2018, 128, 1581-1596. [CrossRef] [PubMed]

44. Kumar, D.P.; Santhekadur, P.K.; Seneshaw, M.; Mirshahi, F.; Tuculescu, C.U.; Sanyal, A.J. A Regulatory Role of Apoptosis Antagonizing Transcription Factor in the Pathogenesis of Nonalcoholic Fatty Liver Disease and Hepatocellular Carcinoma. Hepatology 2019, 69, 1520-1534. [CrossRef]

45. Patel, S.H.; Camargo, F.D.; Yimlamai, D. Hippo Signaling in the Liver Regulates Organ Size, Cell Fate, and Carcinogenesis. Gastroenterology 2016, 152, 533-545. [CrossRef] [PubMed]

46. Souza-Mello, V. Peroxisome proliferator-activated receptors as targets to treat non-alcoholic fatty liver disease. World J. Hepatol. 2015, 7, 1012-1019. [CrossRef] 
47. Ip, E.; Farrell, G.; Robertson, G.; Hall, P.; Kirsch, R.; Leclercq, I. Central role of PPAR $\alpha$-dependent hepatic lipid turnover in dietary steatohepatitis in mice. Hepatology 2003, 38, 123-132. [CrossRef]

48. Musso, G.; Gambino, R.; Cassader, M.; Pagano, G. A meta-analysis of randomized trials for the treatment of nonalcoholic fatty liver disease. Hepatology 2010, 52, 79-104. [CrossRef]

49. Lee, Y.K.; Park, J.E.; Lee, M.; Hardwick, J.P. Hepatic lipid homeostasis by peroxisome proliferator-activated receptor gamma 2ઐ. Liver Res. 2018, 2, 209-215. [CrossRef]

50. Greenstein, A.W.; Majumdar, N.; Yang, P.; Subbaiah, P.V.; Kineman, R.D.; Cordoba-Chacon, J. Hepatocyte-specific, PPAR $\gamma$-regulated mechanisms to promote steatosis in adult mice. J. Endocrinol. 2016, 232, 107-121. [CrossRef]

51. Medina-Gómez, G.; Gray, S.L.; Yetukuri, L.; Shimomura, K.; Virtue, S.; Campbell, M.; Curtis, R.K.; Jimenez-Liñan, M.; Blount, M.; Yeo, G.S.H.; et al. PPAR gamma 2 Prevents Lipotoxicity by Controlling Adipose Tissue Expandability and Peripheral Lipid Metabolism. PLoS Genet. 2007, 3, e64. [CrossRef] [PubMed]

52. Morán-Salvador, E.; López-Parra, M.; García-Alonso, V.; Titos, E.; Martínez-Clemente, M.; González-Périz, A.; López-Vicario, C.; Barak, Y.; Arroyo, V.; Claria, J. Role for PPAR $\gamma$ in obesity-induced hepatic steatosis as determined by hepatocyte- and macrophage-specific conditional knockouts. FASEB J. 2011, 25, 2538-2550. [CrossRef] [PubMed]

53. Matsusue, K.; Haluzík, M.; Lambert, G.; Yim, S.-H.; Gavrilova, O.; Ward, J.M.; Brewer, B.; Reitman, M.L.; Gonzalez, F.J. Liver-specific disruption of PPAR $\gamma$ in leptin-deficient mice improves fatty liver but aggravates diabetic phenotypes. J. Clin. Investig. 2003, 111, 737-747. [CrossRef]

54. Pettinelli, P.; Videla, L. Up-Regulation of PPAR- $\gamma$ mRNA Expression in the Liver of Obese Patients: An Additional Reinforcing Lipogenic Mechanism to SREBP-1c Induction. J. Clin. Endocrinol. Metab. 2011, 96, 1424-1430. [CrossRef] [PubMed]

55. Pan, X.; Wang, P.; Luo, J.; Wang, Z.; Song, Y.; Ye, J.; Hou, X. Adipogenic changes of hepatocytes in a high-fat diet-induced fatty liver mice model and non-alcoholic fatty liver disease patients. Endocrine 2014, 48, 834-847. [CrossRef] [PubMed]

56. Ratziu, V.; Charlotte, F.; Bernhardt, C.; Giral, P.; Halbron, M.; Lenaour, G.; Hartmann-Heurtier, A.; Bruckert, E.; Poynard, T.; LIDO Study Group. Long-term efficacy of rosiglitazone in nonalcoholic steatohepatitis: Results of the fatty liver improvement by rosiglitazone therapy (FLIRT 2) extension trial. Hepatology 2009, 51, 445-453. [CrossRef]

57. Ratziu, V.; Giral, P.; Jacqueminet, S.; Charlotte, F.; Hartemann-Heurtier, A.; Serfaty, L.; Podevin, P.; Lacorte, J.; Bernhardt, C.; Bruckert, E.; et al. Rosiglitazone for Nonalcoholic Steatohepatitis: One-Year Results of the Randomized Placebo-Controlled Fatty Liver Improvement With Rosiglitazone Therapy (FLIRT) Trial. Gastroenterology 2008, 135, 100-110. [CrossRef]

58. Cusi, K.; Orsak, B.; Bril, F.; Lomonaco, R.; Hecht, J.; Ortiz-Lopez, C.; Tio, F.; Hardies, J.; Darland, C.; Musi, N.; et al. Long-Term Pioglitazone Treatment for Patients With Nonalcoholic Steatohepatitis and Prediabetes or Type 2 Diabetes Mellitus. Ann. Intern. Med. 2016, 165, 305. [CrossRef]

59. Feige, J.N.; Gelman, L.; Tudor, C.; Engelborghs, Y.; Wahli, W.; Desvergne, B. Fluorescence Imaging Reveals the Nuclear Behavior of Peroxisome Proliferator-activated Receptor/Retinoid X Receptor Heterodimers in the Absence and Presence of Ligand. J. Biol. Chem. 2005, 280, 17880-17890. [CrossRef]

60. Kliewer, S.A.; Forman, B.M.; Blumberg, B.; Ong, E.S.; Borgmeyer, U.; Mangelsdorf, D.J.; Umesono, K.; Evans, R.M. Differential expression and activation of a family of murine peroxisome proliferator-activated receptors. Proc. Natl. Acad. Sci. USA 1994, 91, 7355-7359. [CrossRef]

61. Bays, H.E.; Schwartz, S.; Littlejohn, T.; Kerzner, B.; Krauss, R.M.; Karpf, D.B.; Choi, Y.-J.; Wang, X.; Naim, S.; Roberts, B.K. MBX-8025, A Novel Peroxisome Proliferator Receptor-? Agonist: Lipid and Other Metabolic Effects in Dyslipidemic Overweight Patients Treated with and without Atorvastatin. J. Clin. Endocrinol. Metab. 2011, 96, 2889-2897. [CrossRef] [PubMed]

62. Riserus, U.; Sprecher, D.; Johnson, T.; Olson, E.; Hirschberg, S.; Liu, A.; Fang, Z.; Hegde, P.; Richards, D.; Sarov-Blat, L.; et al. Activation of Peroxisome Proliferator-Activated Receptor (PPAR) Promotes Reversal of Multiple Metabolic Abnormalities, Reduces Oxidative Stress, and Increases Fatty Acid Oxidation in Moderately Obese Men. Diabetes 2007, 57, 332-339. [CrossRef] [PubMed]

63. Shimano, H. SREBPs: Physiology and pathophysiology of the SREBP family. FEBS J. 2008, 276, 616-621. [CrossRef] [PubMed] 
64. Fatehi-Hassanabad, Z.; Chan, C.B. Transcriptional regulation of lipid metabolism by fatty acids: A key determinant of pancreatic $\beta$-cell function. Nutr. Metab. 2005, 2, 1. [CrossRef] [PubMed]

65. Walker, A.K.; Yang, F.; Jiang, K.; Ji, J.-Y.; Watts, J.L.; Purushotham, A.; Boss, O.; Hirsch, M.L.; Ribich, S.; Smith, J.J.; et al. Conserved role of SIRT1 orthologs in fasting-dependent inhibition of the lipid/cholesterol regulator SREBP. Genes Dev. 2010, 24, 1403-1417. [CrossRef]

66. Bruschi, F.V.; Tardelli, M.; Claudel, T.; Trauner, M. PNPLA3 expression and its impact on the liver: Current perspectives. Hepatic Med. 2017, 9, 55-66. [CrossRef] [PubMed]

67. Cohen, J.C.; Horton, J.D.; Hobbs, H.H. Human Fatty Liver Disease: Old Questions and New Insights. Science 2011, 332, 1519-1523. [CrossRef]

68. Dongiovanni, P.; Donati, B.; Fares, R.; Lombardi, R.; Mancina, R.M.; Romeo, S.; Valenti, L. PNPLA3 I148M polymorphism and progressive liver disease. World J. Gastroenterol. 2013, 19, 6969-6978. [CrossRef]

69. Sookoian, S.; Pirola, C.J. Meta-analysis of the influence of I148M variant of patatin-like phospholipase domain containing 3 gene (PNPLA3) on the susceptibility and histological severity of nonalcoholic fatty liver disease. Hepatology 2011, 53, 1883-1894. [CrossRef]

70. Kohjima, M.; Higuchi, N.; Kato, M.; Kotoh, K.; Yoshimoto, T.; Fujino, T.; Yada, M.; Yada, R.; Harada, N.; Enjoji, M.; et al. SREBP-1c, regulated by the insulin and AMPK signaling pathways, plays a role in nonalcoholic fatty liver disease. Int. J. Mol. Med. 2008, 21, 507-511. [CrossRef]

71. Horton, J.D.; Goldstein, J.L.; Brown, M.S. SREBPs: Activators of the complete program of cholesterol and fatty acid synthesis in the liver. J. Clin. Investig. 2002, 109, 1125-1131. [CrossRef]

72. Kim, J.Y.; Garcia-Carbonell, R.; Yamachika, S.; Zhao, P.; Dhar, D.; Loomba, R.; Kaufman, R.J.; Saltiel, A.R.; Karin, M. ER Stress Drives Lipogenesis and Steatohepatitis via Caspase-2 Activation of S1P. Cell 2018, 175, 133-145.e15. [CrossRef] [PubMed]

73. Caballero, F.; Fernandez, A.; De Lacy, A.M.; Fernándezcheca, J.C.; Caballería, J.; García-Ruiz, C. Enhanced free cholesterol, SREBP-2 and StAR expression in human NASH. J. Hepatol. 2009, 50, 789-796. [CrossRef] [PubMed]

74. Ueda, A.; Hamadeh, H.K.; Webb, H.K.; Yamamoto, Y.; Sueyoshi, T.; Afshari, C.A.; Lehmann, J.M.; Negishi, M. Diverse roles of the nuclear orphan receptor CAR in regulating hepatic genes in response to phenobarbital. Mol. Pharmacol. 2002, 61,1-6. [CrossRef] [PubMed]

75. Gao, J.; He, J.; Zhai, Y.; Wada, T.; Xie, W. The Constitutive Androstane Receptor Is an Anti-obesity Nuclear Receptor That Improves Insulin Sensitivity*. J. Biol. Chem. 2009, 284, 25984-25992. [CrossRef]

76. Dong, B.; Saha, P.K.; Huang, W.; Chen, W.; Abu-Elheiga, L.; Wakil, S.J.; Stevens, R.D.; Ilkayeva, O.; Newgard, C.B.; Chan, L.; et al. Activation of nuclear receptor CAR ameliorates diabetes and fatty liver disease. Proc. Natl. Acad. Sci. USA 2009, 106, 18831-18836. [CrossRef] [PubMed]

77. Patel, M.B.; Oza, N.A.; Anand, I.S.; Deshpande, S.S.; Patel, C.N. Liver X Receptor: A Novel Therapeutic Target. Indian J. Pharm. Sci. 2008, 70, 135-144. [CrossRef]

78. Han, C.Y. Update on FXR Biology: Promising Therapeutic Target? Int. J. Mol. Sci. 2018, 19, 2069. [CrossRef]

79. Park, J.-G.; Xu, X.; Cho, S.; Hur, K.Y.; Lee, M.-S.; Kersten, S.; Lee, A.-H. CREBH-FGF21 axis improves hepatic steatosis by suppressing adipose tissue lipolysis. Sci. Rep. 2016, 6, 27938. [CrossRef]

80. Nakagawa, Y.; Shimano, H. CREBH Regulates Systemic Glucose and Lipid Metabolism. Int. J. Mol. Sci. 2018, 19, 1396. [CrossRef]

81. Lee, M.-W.; Chanda, D.; Yang, J.; Oh, H.; Kim, S.S.; Yoon, Y.-S.; Hong, S.; Park, K.; Lee, I.-K.; Choi, C.S.; et al. Regulation of Hepatic Gluconeogenesis by an ER-Bound Transcription Factor, CREBH. Cell Metab. 2010, 11,331-339. [CrossRef]

82. Danno, H.; Ishii, K.-A.; Nakagawa, Y.; Mikami, M.; Yamamoto, T.; Yabe, S.; Furusawa, M.; Kumadaki, S.; Watanabe, K.; Shimizu, H.; et al. The liver-enriched transcription factor CREBH is nutritionally regulated and activated by fatty acids and PPAR $\alpha$. Biochem. Biophys. Res. Commun. 2010, 391, 1222-1227. [CrossRef] [PubMed]

83. Xu, X.; Park, J.-G.; So, J.-S.; Hur, K.Y.; Lee, A.-H. Transcriptional regulation of apolipoprotein A-IV by the transcription factor CREBH. J. Lipid Res. 2014, 55, 850-859. [CrossRef] [PubMed]

84. Cheng, N.; Xu, X.; Simon, T.; Boudyguina, E.; Deng, Z.; Verhague, M.; Lee, A.-H.; Shelness, G.S.; Weinberg, R.B.; Parks, J.S. Very Low Density Lipoprotein Assembly Is Required for cAMP-responsive Element-binding Protein H Processing and Hepatic Apolipoprotein A-IV Expression. J. Biol. Chem. 2016, 291, 23793-23803. [CrossRef] [PubMed] 
85. Lee, J.H.; Giannikopoulos, P.; Duncan, S.A.; Wang, J.; Johansen, C.T.; Brown, J.D.; Plutzky, J.; Hegele, R.A.; Glimcher, L.H.; Lee, A.-H. The transcription factor cyclic AMP-responsive element-binding protein $\mathrm{H}$ regulates triglyceride metabolism. Nat. Med. 2011, 17, 812-815. [CrossRef] [PubMed]

86. Zhang, C.; Wang, G.; Zheng, Z.; Maddipati, K.R.; Zhang, X.; Dyson, G.; Williams, P.; Duncan, S.A.; Kaufman, R.J.; Zhang, K. Endoplasmic reticulum-tethered transcription factor cAMP responsive element-binding protein, hepatocyte specific, regulates hepatic lipogenesis, fatty acid oxidation, and lipolysis upon metabolic stress in mice. Hepatology 2012, 55, 1070-1082. [CrossRef] [PubMed]

87. Satoh, A.; Han, S.-I.; Araki, M.; Nakagawa, Y.; Ohno, H.; Mizunoe, Y.; Kumagai, K.; Murayama, Y.; Osaki, Y.; Iwasaki, H.; et al. CREBH Improves Diet-Induced Obesity, Insulin Resistance, and Metabolic Disturbances by FGF21-Dependent and FGF21-Independent Mechanisms. iScience 2020, 23, 100930. [CrossRef] [PubMed]

88. Zhang, Y.; Kast-Woelbern, H.R.; Edwards, P.A. Natural Structural Variants of the Nuclear Receptor Farnesoid $X$ Receptor Affect Transcriptional Activation. J. Biol. Chem. 2002, 278, 104-110. [CrossRef]

89. Xi, Y.; Li, H. Role of farnesoid $\mathrm{X}$ receptor in hepatic steatosis in nonalcoholic fatty liver disease. Biomed. Pharmacother. 2020, 121, 109609. [CrossRef]

90. Kalaany, N.Y.; Mangelsdorf, D.J. LXRS AND FXR: The Yin and Yang of Cholesterol and Fat Metabolism. Annu. Rev. Physiol. 2006, 68, 159-191. [CrossRef]

91. Jiao, Y.; Lu, Y.; Li, X.-Y. Farnesoid X receptor: A master regulator of hepatic triglyceride and glucose homeostasis. Acta Pharmacol. Sin. 2014, 36, 44-50. [CrossRef] [PubMed]

92. Barclay, J.; Nelson, C.N.; Ishikawa, M.; Murray, L.A.; Kerr, L.M.; McPhee, T.R.; Powell, E.E.; Waters, M.J. GH-Dependent STAT5 Signaling Plays an Important Role in Hepatic Lipid Metabolism. Endocrinology 2011, 152, 181-192. [CrossRef] [PubMed]

93. Baik, M.; Nam, Y.S.; Piao, M.; Kang, H.J.; Park, S.J.; Lee, J.-H. Liver-specific deletion of the signal transducer and activator of transcription 5 gene aggravates fatty liver in response to a high-fat diet in mice. J. Nutr. Biochem. 2016, 29, 56-63. [CrossRef] [PubMed]

94. Ko, C.-Y.; Chang, W.-C.; Wang, J.-M. Biological roles of CCAAT/Enhancer-binding protein delta during inflammation. J. Biomed. Sci. 2015, 22, 6. [CrossRef] [PubMed]

95. Matsusue, K.; Gavrilova, O.; Lambert, G.; Brewer, H.B.; Ward, J.M.; Inoue, Y.; Leroith, D.; Gonzalez, F.J. Hepatic CCAAT/Enhancer Binding Protein $\alpha$ Mediates Induction of Lipogenesis and Regulation of Glucose Homeostasis in Leptin-Deficient Mice. Mol. Endocrinol. 2004, 18, 2751-2764. [CrossRef] [PubMed]

96. Yoon, J.C.; Puigserver, P.; Chen, G.; Donovan, J.; Wu, Z.; Rhee, J.; Adelmant, G.; Stafford, J.M.; Kahn, C.R.; Granner, D.K.; et al. Control of hepatic gluconeogenesis through the transcriptional coactivator PGC-1. Nature 2001, 413, 131-138. [CrossRef] [PubMed]

97. Yu, Y.; Maguire, T.G.; Alwine, J.C. ChREBP, a glucose-responsive transcriptional factor, enhances glucose metabolism to support biosynthesis in human cytomegalovirus-infected cells. Proc. Natl. Acad. Sci. USA 2014, 111, 1951-1956. [CrossRef]

98. Kim, M.-S.; Krawczyk, S.A.; Doridot, L.; Fowler, A.J.; Wang, J.X.; Trauger, S.A.; Noh, H.-L.; Kang, H.J.; Meissen, J.K.; Blatnik, M.; et al. ChREBP regulates fructose-induced glucose production independently of insulin signaling. J. Clin. Investig. 2016, 126, 4372-4386. [CrossRef]

99. Herman, M.A.; Peroni, O.D.; Villoria, J.; Schön, M.R.; Abumrad, N.A.; Blüher, M.; Klein, S.; Kahn, B.B. A novel ChREBP isoform in adipose tissue regulates systemic glucose metabolism. Nature 2012, 484, 333-338. [CrossRef]

100. Xu, X.; So, J.-S.; Park, J.-G.; Lee, A.-H. Transcriptional control of hepatic lipid metabolism by SREBP and ChREBP. Semin. Liver Dis. 2013, 33, 301-311. [CrossRef]

101. Austin, S.; St-Pierre, J. PGC1 and mitochondrial metabolism-Emerging concepts and relevance in ageing and neurodegenerative disorders. J. Cell Sci. 2012, 125, 4963-4971. [CrossRef] [PubMed]

102. Aharoni-Simon, M.; Hann-Obercyger, M.; Pen, S.; Madar, Z.; Tirosh, O. Fatty liver is associated with impaired activity of PPAR $\gamma$-coactivator $1 \alpha(\mathrm{PGC} 1 \alpha)$ and mitochondrial biogenesis in mice. Lab. Investig. 2011, 91, 1018-1028. [CrossRef] [PubMed]

103. Erion, D.M.; Ignatova, I.D.; Yonemitsu, S.; Nagai, Y.; Chatterjee, P.; Weismann, D.; Hsiao, J.J.; Zhang, D.; Iwasaki, T.; Stark, R.; et al. Prevention of Hepatic Steatosis and Hepatic Insulin Resistance by Knockdown of cAMP Response Element-Binding Protein. Cell Metab. 2009, 10, 499-506. [CrossRef] [PubMed]

104. Carter, M.E.; Brunet, A. FOXO transcription factors. Curr. Biol. 2007, 17, R113-R114. [CrossRef] 


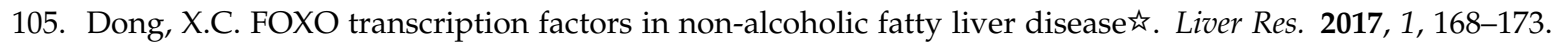
[CrossRef]

106. Sparks, J.; Dong, H.H. FoxO1 and hepatic lipid metabolism. Curr. Opin. Lipidol. 2009, 20, 217-226. [CrossRef]

107. Lu, H. Crosstalk of HNF4 $\alpha$ with extracellular and intracellular signaling pathways in the regulation of hepatic metabolism of drugs and lipids. Acta Pharm. Sin. B 2016, 6, 393-408. [CrossRef]

108. Liu, H.; Lou, G.; Li, C.; Wang, X.; Cederbaum, A.I.; Gan, L.; Xie, B. HBx Inhibits CYP2E1 Gene Expression via Downregulating HNF4 $\alpha$ in Human Hepatoma Cells. PLoS ONE 2014, 9, e107913. [CrossRef]

109. Yu, D.; Chen, G.; Pan, M.; Zhang, J.; He, W.; Liu, Y.; Nian, X.; Sheng, L.; Xu, B. High fat diet-induced oxidative stress blocks hepatocyte nuclear factor $4 \alpha$ and leads to hepatic steatosis in mice. J. Cell. Physiol. 2018, 233, 4770-4782. [CrossRef]

110. Ravnskjaer, K.; Frigerio, F.; Boergesen, M.; Nielsen, T.; Maechler, P.; Mandrup, S. PPAR $\delta$ is a fatty acid sensor that enhances mitochondrial oxidation in insulin-secreting cells and protects against fatty acid-induced dysfunction. J. Lipid Res. 2009, 51, 1370-1379. [CrossRef]

111. Iglesias, J.; Barg, S.; Vallois, D.; Lahiri, S.; Roger, C.; Yessoufou, A.; Pradevand, S.; McDonald, A.; Bonal, C.; Reimann, F.; et al. PPAR $\beta / \delta$ affects pancreatic $\beta$ cell mass and insulin secretion in mice. J. Clin. Investig. 2012, 122, 4105-4117. [CrossRef] [PubMed]

112. Lee, C.-H.; Olson, P.; Hevener, A.; Mehl, I.; Chong, L.-W.; Olefsky, J.M.; Gonzalez, F.J.; Ham, J.; Kang, H.; Peters, J.M.; et al. PPAR $\delta$ regulates glucose metabolism and insulin sensitivity. Proc. Natl. Acad. Sci. USA 2006, 103, 3444-3449. [CrossRef] [PubMed]

113. Tanaka, T.; Yamamoto, J.; Iwasaki, S.; Asaba, H.; Hamura, H.; Ikeda, Y.; Watanabe, M.; Magoori, K.; Ioka, R.X.; Tachibana, K.; et al. Activation of peroxisome proliferator-activated receptor $\delta$ induces fatty acid $\beta$-oxidation in skeletal muscle and attenuates metabolic syndrome. Proc. Natl. Acad. Sci. USA 2003, 100, 15924-15929. [CrossRef] [PubMed]

114. Smale, S.T.; Natoli, G. Transcriptional Control of Inflammatory Responses. Cold Spring Harb. Perspect. Biol. 2014, 6, a016261. [CrossRef]

115. Karin, M.; Yamamoto, Y.; Wang, Q.M. The IKK NF-кB system: A treasure trove for drug development. Nat. Rev. Drug Discov. 2004, 3, 17-26. [CrossRef]

116. Pena, A.D.; Leclercq, I.; Field, J.; George, J.; Jones, B.; Farrell, G. NF-кB Activation, Rather Than TNF, Mediates Hepatic Inflammation in a Murine Dietary Model of Steatohepatitis. Gastroenterology 2005, 129, 1663-1674. [CrossRef]

117. Ribeiro, P.S.; Cortez-Pinto, H.; Solá, S.; Castro, R.E.; Ramalho, R.; Baptista, A.; Moura, M.C.; Camilo, M.E.; Rodrigues, C.M.P.; Baptista, A. Hepatocyte Apoptosis, Expression of Death Receptors, and Activation of NF-кB in the Liver of Nonalcoholic and Alcoholic Steatohepatitis Patients. Am. J. Gastroenterol. 2004, 99, 1708-1717. [CrossRef]

118. Wang, X.-A.; Zhang, R.; Zhang, S.; Deng, S.; Jiang, D.; Zhong, J.; Yang, L.; Wang, T.; Hong, S.; Guo, S.; et al. Interferon regulatory factor 7 deficiency prevents diet-induced obesity and insulin resistance. Am. J. Physiol. Metab. 2013, 305, E485-E495. [CrossRef]

119. Iyer, S.; Upadhyay, P.K.; Majumdar, S.S.; Nagarajan, P. Animal Models Correlating Immune Cells for the Development of NAFLD/NASH. J. Clin. Exp. Hepatol. 2015, 5, 239-245. [CrossRef]

120. Ferreira, D.M.S.; Castro, R.E.; Machado, M.V.; Evangelista, T.; Silvestre, A.; Costa, A.; Coutinho, J.; Carepa, F.; Cortez-Pinto, H.; Rodrigues, C.M.P. Apoptosis and insulin resistance in liver and peripheral tissues of morbidly obese patients is associated with different stages of non-alcoholic fatty liver disease. Diabetology 2011, 54, 1788-1798. [CrossRef]

121. Schreck, I.; Al-Rawi, M.; Mingot, J.-M.; Scholl, C.; Diefenbacher, M.E.; O’Donnell, P.; Bohmann, D.; Weiss, C. c-Jun localizes to the nucleus independent of its phosphorylation by and interaction with JNK and vice versa promotes nuclear accumulation of JNK. Biochem. Biophys. Res. Commun. 2011, 407, 735-740. [CrossRef] [PubMed]

122. Bruno, T.; Iezzi, S.; De Nicola, F.; Di Padova, M.; DeSantis, A.; Scarsella, M.; Di Certo, M.G.; Leonetti, C.; Floridi, A.; Passananti, C.; et al. Che-1 activates XIAP expression in response to DNA damage. Cell Death Differ. 2007, 15, 515-520. [CrossRef]

123. DeSantis, A.; Bruno, T.; Catena, V.; De Nicola, F.; Goeman, F.; Iezzi, S.; Sorino, C.; Ponzoni, M.; Bossi, G.; Federico, V.; et al. Che-1-induced inhibition of mTOR pathway enables stress-induced autophagy. EMBO J. 2015, 34, 1214-1230. [CrossRef] [PubMed] 
124. DeSantis, A.; Bruno, T.; Catena, V.; De Nicola, F.; Goeman, F.; Iezzi, S.; Sorino, C.; Gentileschi, M.P.; Germoni, S.; Monteleone, V.; et al. Che-1 modulates the decision between cell cycle arrest and apoptosis by its binding to p53. Cell Death Dis. 2015, 6, e1764. [CrossRef] [PubMed]

125. Zhang, K.; Wang, S.; Malhotra, J.; Hassler, J.R.; Back, S.H.; Wang, G.; Chang, L.; Xu, W.; Miao, H.; Leonardi, R.; et al. The unfolded protein response transducer IRE1 $\alpha$ prevents ER stress-induced hepatic steatosis. EMBO J. 2011, 30, 1357-1375. [CrossRef] [PubMed]

126. Yuk, J.-M.; Shin, N.-M.; Lee, H.-M.; Kim, J.-J.; Kim, S.-W.; Jin, H.S.; Yang, C.-S.; Park, K.A.; Chanda, D.; Kim, N.-K.; et al. The orphan nuclear receptor SHP acts as a negative regulator in inflammatory signaling triggered by Toll-like receptors. Nat. Immunol. 2011, 12, 742-751. [CrossRef]

127. Yang, C.-S.; Kim, J.-J.; Kim, T.S.; Jo, E.-K.; Kim, S.Y.; Lee, H.-M.; Shin, N.-M.; Nguyen, L.T.; Lee, M.-S.; Jin, H.S.; et al. Small heterodimer partner interacts with NLRP3 and negatively regulates activation of the NLRP3 inflammasome. Nat. Commun. 2015, 6, 6115. [CrossRef] [PubMed]

128. Poli, V. The Role of C/EBP Isoforms in the Control of Inflammatory and Native Immunity Functions. J. Biol. Chem. 1998, 273, 29279-29282. [CrossRef]

129. Berghe, W.V.; Vermeulen, L.; Delerive, P.; De Bosscher, K.; Staels, B.; Haegeman, G. A Paradigm for Gene Regulation: Inflammation, NF-kB and PPAR. Adv. Exp. Med. Biol. 2003, 544, 181-196. [CrossRef]

130. Stienstra, R.; Mandard, S.; Patsouris, D.; Maass, C.; Kersten, S.; Muller, M. Peroxisome Proliferator-Activated Receptor $\alpha$ Protects against Obesity-Induced Hepatic Inflammation. Endocrinology 2007, 148, 2753-2763. [CrossRef]

131. Ricote, M.; Li, A.C.; Willson, T.M.; Kelly, C.J.; Glass, C.K. The peroxisome proliferator-activated receptor- $\gamma$ is a negative regulator of macrophage activation. Nature 1998, 391, 79-82. [CrossRef] [PubMed]

132. Morán-Salvador, E.; Titos, E.; Rius, B.; González-Périz, A.; García-Alonso, V.; López-Vicario, C.; Miquel, R.; Barak, Y.; Arroyo, V.; Claria, J. Cell-specific PPAR $\gamma$ deficiency establishes anti-inflammatory and anti-fibrogenic properties for this nuclear receptor in non-parenchymal liver cells. J. Hepatol. 2013, 59, 1045-1053. [CrossRef]

133. Luo, W.; Xu, Q.; Wang, Q.; Wu, H.; Hua, J. Effect of modulation of PPAR- $\gamma$ activity on Kupffer cells M1/M2 polarization in the development of non-alcoholic fatty liver disease. Sci. Rep. 2017, 7, 44612. [CrossRef] [PubMed]

134. Baskin-Bey, E.S.; Anan, A.; Isomoto, H.; Bronk, S.F.; Gores, G.J. Constitutive androstane receptor agonist, TCPOBOP, attenuates steatohepatitis in the methionine choline-deficient diet-fed mouse. World J. Gastroenterol. 2007, 13, 5635-5641. [CrossRef] [PubMed]

135. Yamazaki, Y.; Kakizaki, S.; Horiguchi, N.; Sohara, N.; Sato, K.; Takagi, H.; Mori, M.; Negishi, M. The role of the nuclear receptor constitutive androstane receptor in the pathogenesis of non-alcoholic steatohepatitis. Gut 2006, 56, 565-574. [CrossRef] [PubMed]

136. Venteclef, N.; Jakobsson, T.; Ehrlund, A.; Damdimopoulos, A.; Mikkonen, L.; Ellis, E.; Nilsson, L.-M.; Parini, P.; Jänne, O.A.; Gustafsson, J.-Å.; et al. GPS2-dependent corepressor/SUMO pathways govern anti-inflammatory actions of LRH-1 and LXR $\beta$ in the hepatic acute phase response. Genes Dev. 2010, 24, 381-395. [CrossRef]

137. Griffett, K.; Solt, L.A.; Elgendy, B.; Kamenecka, T.M.; Burris, T.P. A Liver-Selective LXR Inverse Agonist That Suppresses Hepatic Steatosis. ACS Chem. Biol. 2012, 8, 559-567. [CrossRef]

138. Griffett, K.; Welch, R.D.; Flaveny, C.A.; Kolar, G.R.; Neuschwander-Tetri, B.A.; Burris, T.P. The LXR inverse agonist SR9238 suppresses fibrosis in a model of non-alcoholic steatohepatitis. Mol. Metab. 2015, 4, 353-357. [CrossRef]

139. Kim, K.H.; Lee, M.-S. Pathogenesis of Nonalcoholic Steatohepatitis and Hormone-Based Therapeutic Approaches. Front. Endocrinol. 2018, 9, 485. [CrossRef]

140. Xu, D.; Xu, M.; Jeong, S.; Qian, Y.; Wu, H.; Xia, Q.; Kong, X. The Role of Nrf2 in Liver Disease: Novel Molecular Mechanisms and Therapeutic Approaches. Front. Pharmacol. 2019, 9, 9. [CrossRef]

141. Lee, J.; Sun, C.; Zhou, Y.; Lee, J.; Gökalp, D.; Herrema, H.; Park, S.W.; Davis, R.J.; Ozcan, U. p38 MAPK-mediated regulation of Xbp1s is crucial for glucose homeostasis. Nat. Med. 2011, 17, 1251-1260. [CrossRef] [PubMed]

142. Herrema, H.; Zhou, Y.; Zhang, D.; Lee, J.; Hernandez, M.A.S.; Shulman, G.I.; Ozcan, U. XBP1s Is an Anti-lipogenic Protein. J. Biol. Chem. 2016, 291, 17394-17404. [CrossRef] [PubMed] 
143. Liu, X.; Henkel, A.S.; Lecuyer, B.E.; Schipma, M.J.; Anderson, K.A.; Green, R.M. Hepatocyte X-box binding protein 1 deficiency increases liver injury in mice fed a high-fat/sugar diet. Am. J. Physiol. Liver Physiol. 2015, 309, G965-G974. [CrossRef] [PubMed]

144. Xiao, G.; Zhang, T.; Yu, S.; Lee, S.; Calabuig-Navarro, V.; Yamauchi, J.; Ringquist, S.; Dong, H.H. ATF4 Protein Deficiency Protects against High Fructose-induced Hypertriglyceridemia in Mice*. J. Biol. Chem. 2013, 288, 25350-25361. [CrossRef]

145. Chen, X.; Zhang, F.; Gong, Q.; Cui, A.; Zhuo, S.; Hu, Z.; Han, Y.; Gao, J.; Sun, Y.; Liu, Z.; et al. Hepatic ATF6 Increases Fatty Acid Oxidation to Attenuate Hepatic Steatosis in Mice through Peroxisome Proliferator-Activated Receptor Alpha. Diabetes 2016, 65, 1904-1915. [CrossRef]

146. Zeng, L.; Lu, M.; Mori, K.; Luo, S.; Lee, A.S.; Zhu, Y.; Shyy, J.Y.-J. ATF6 modulates SREBP2-mediated lipogenesis. EMBO J. 2004, 23, 950-958. [CrossRef]

147. Tang, W.; Jiang, Y.-F.; Ponnusamy, M.; Diallo, M. Role of Nrf2 in chronic liver disease. World J. Gastroenterol. 2014, 20, 13079-13087. [CrossRef]

148. Gupte, A.A.; Lyon, C.J.; Hsueh, W.A. Nuclear Factor (Erythroid-Derived 2)-Like-2 Factor (Nrf2), a Key Regulator of the Antioxidant Response to Protect Against Atherosclerosis and Nonalcoholic Steatohepatitis. Curr. Diabetes Rep. 2013, 13, 362-371. [CrossRef]

149. Sharma, R.S.; Harrison, D.J.; Kisielewski, D.; Cassidy, D.M.; McNeilly, A.D.; Gallagher, J.R.; Walsh, S.V.; Honda, T.; McCrimmon, R.J.; Dinkova-Kostova, A.T.; et al. Experimental Nonalcoholic Steatohepatitis and Liver Fibrosis Are Ameliorated by Pharmacologic Activation of Nrf2 (NF-E2 p45-Related Factor 2). Cell. Mol. Gastroenterol. Hepatol. 2017, 5, 367-398. [CrossRef]

150. Chowdhry, S.; Nazmy, M.H.; Meakin, P.J.; Dinkova-Kostova, A.T.; Walsh, S.V.; Tsujita, T.; Dillon, J.; Ashford, M.L.; Hayes, J. Loss of Nrf2 markedly exacerbates nonalcoholic steatohepatitis. Free Radic. Biol. Med. 2010, 48, 357-371. [CrossRef]

151. Liu, Z.; Dou, W.; Ni, Z.; Wen, Q.; Zhang, R.; Qin, M.; Wang, X.; Tang, H.; Cao, Y.; Wang, J.; et al. Deletion of $\mathrm{Nrf} 2$ leads to hepatic insulin resistance via the activation of NF-kB in mice fed a high-fat diet. Mol. Med. Rep. 2016, 14, 1323-1331. [CrossRef] [PubMed]

152. Woodcroft, K.J.; Hafner, M.S.; Novak, R.F. Insulin signaling in the transcriptional and posttranscriptional regulation of CYP2E1 expression. Hepatology 2002, 35, 263-273. [CrossRef] [PubMed]

153. Leung, T.-M.; Nieto, N. CYP2E1 and oxidant stress in alcoholic and non-alcoholic fatty liver disease. J. Hepatol. 2013, 58, 395-398. [CrossRef] [PubMed]

154. Kelicen, P.; Tindberg, N. Lipopolysaccharide Induces CYP2E1 in Astrocytes through MAP Kinase Kinase-3 and C/EBPbeta and -Delta. J. Biol. Chem. 2003, 279, 15734-15742. [CrossRef]

155. Daly, A.K. Relevance of CYP2E1 to Non-alcoholic Fatty Liver Disease. Membr. Biog. 2013, 67, $165-175$. [CrossRef]

156. Svegliati-Baroni, G.; Pierantonelli, I.; Torquato, P.; Marinelli, R.; Ferreri, C.; Chatgilialoglu, C.; Bartolini, D.; Galli, F. Lipidomic biomarkers and mechanisms of lipotoxicity in non-alcoholic fatty liver disease. Free Radic. Biol. Med. 2019, 144, 293-309. [CrossRef]

157. Aubert, J.; Begriche, K.; Knockaert, L.; Robin, M.; Fromenty, B. Increased expression of cytochrome P450 2E1 in nonalcoholic fatty liver disease: Mechanisms and pathophysiological role. Clin. Res. Hepatol. Gastroenterol. 2011, 35, 630-637. [CrossRef]

158. Liu, S.-Y.; Gonzalez, F.J. Role of the Liver-Enriched Transcription Factor HNF-1 $\alpha$ in Expression of theCYP2E1Gene. DNA Cell Biol. 1995, 14, 285-293. [CrossRef]

159. Jin, M.; Ande, A.; Kumar, A.; Kumar, S. Regulation of cytochrome P450 2e1 expression by ethanol: Role of oxidative stress-mediated pkc/jnk/sp1 pathway. Cell Death Dis. 2013, 4, e554. [CrossRef]

160. Tsuchida, T.; Friedman, S.L. Mechanisms of hepatic stellate cell activation. Nat. Rev. Gastroenterol. Hepatol. 2017, 14, 397-411. [CrossRef]

161. Koyama, Y.; Xu, J.; Liu, X.; Brenner, D.A. New Developments on the Treatment of Liver Fibrosis. Dig. Dis. 2016, 34, 589-596. [CrossRef]

162. Meng, X.-M.; Nikolic-Paterson, D.J.; Lan, H.-Y. TGF- $\beta$ : The master regulator of fibrosis. Nat. Rev. Nephrol. 2016, 12, 325-338. [CrossRef] [PubMed]

163. Wobser, H.; Dorn, C.; Weiss, T.S.; Amann, T.; Bollheimer, C.; Büttner, R.; Schölmerich, J.; Hellerbrand, C. Lipid accumulation in hepatocytes induces fibrogenic activation of hepatic stellate cells. Cell Res. 2009, 19, 996-1005. [CrossRef] [PubMed] 
164. Xu, P.; Liu, J.; Derynck, R. Post-translational regulation of TGF- $\beta$ receptor and Smad signaling. FEBS Lett. 2012, 586, 1871-1884. [CrossRef]

165. Inoue, Y.; Itoh, Y.; Abe, K.; Okamoto, T.; Daitoku, H.; Fukamizu, A.; Onozaki, K.; Hayashi, H. Smad3 is acetylated by p300/CBP to regulate its transactivation activity. Oncogene 2006, 26, 500-508. [CrossRef] [PubMed]

166. Lim, J.-Y.; Oh, M.-A.; Kim, W.H.; Sohn, H.-Y.; Park, S.I. AMP-activated protein kinase inhibits TGF-?-induced fibrogenic responses of hepatic stellate cells by targeting transcriptional coactivator p300. J. Cell. Physiol. 2011, 227, 1081-1089. [CrossRef] [PubMed]

167. Liu, E.; Liu, Z.; Zhou, Y.; Chen, M.; Wang, L.; Li, J. MicroRNA-142-3p inhibits trophoblast cell migration and invasion by disrupting the TGF- $\beta 1 /$ Smad3 signaling pathway. Mol. Med. Rep. 2019, 19, 3775-3782. [CrossRef]

168. Gerhard, G.S.; Hanson, A.; Wilhelmsen, D.; Piras, I.S.; Still, C.D.; Chu, X.; Petrick, A.T.; Distefano, J.K. AEBP1 expression increases with severity of fibrosis in NASH and is regulated by glucose, palmitate, and miR-372-3p. PLoS ONE 2019, 14, e0219764. [CrossRef]

169. Kim, S.-W.; Muise, A.M.; Lyons, P.J.; Ro, H.-S. Regulation of Adipogenesis by a Transcriptional Repressor That Modulates MAPK Activation. J. Biol. Chem. 2001, 276, 10199-10206. [CrossRef]

170. Jager, M.; Lee, M.-J.; Li, C.; Farmer, S.R.; Fried, S.K.; Layne, M.D. Aortic carboxypeptidase-like protein enhances adipose tissue stromal progenitor differentiation into myofibroblasts and is upregulated in fibrotic white adipose tissue. PLoS ONE 2018, 13, e0197777. [CrossRef]

171. Majdalawieh, A.; Zhang, L.; Fuki, I.V.; Rader, D.J.; Ro, H.-S. Adipocyte enhancer-binding protein 1 is a potential novel atherogenic factor involved in macrophage cholesterol homeostasis and inflammation. Proc. Natl. Acad. Sci. USA 2006, 103, 2346-2351. [CrossRef] [PubMed]

172. Lou, Y.; Chen, Y.-D.; Sun, F.-R.; Shi, J.-P.; Song, Y.; Yang, J. Potential Regulators Driving the Transition in Nonalcoholic Fatty Liver Disease: A Stage-Based View. Cell. Physiol. Biochem. 2017, 41, 239-251. [CrossRef] [PubMed]

173. Camargo, F.D.; Gokhale, S.; Johnnidis, J.B.; Fu, N.; Bell, G.W.; Jaenisch, R.; Brummelkamp, T.R. YAP1 Increases Organ Size and Expands Undifferentiated Progenitor Cells. Curr. Biol. 2007, 17, 2054-2060. [CrossRef] [PubMed]

174. Mooring, M.; Fowl, B.H.; Lum, S.Z.C.; Liu, Y.; Yao, K.; Softic, S.; Kirchner, R.; Bernstein, A.; Singhi, A.D.; Jay, D.G.; et al. Hepatocyte Stress Increases Expression of YAP and TAZ in Hepatocytes to Promote Parenchymal Inflammation and Fibrosis. Hepatology 2019. [CrossRef]

175. Song, K.; Kwon, H.; Han, C.; Chen, W.; Zhang, J.; Ma, W.; Dash, S.; Gandhi, C.R.; Wu, T. YAP in Kupffer cells enhances the production of pro-inflammatory cytokines and promotes the development of non-alcoholic steatohepatitis. Hepatology 2019. [CrossRef] [PubMed]

176. Abdelmegeed, M.A.; Yoo, S.-H.; Henderson, L.E.; Gonzalez, F.J.; Woodcroft, K.J.; Song, B.-J. PPARalpha expression protects male mice from high fat-induced nonalcoholic fatty liver. J. Nutr. 2011, 141, 603-610. [CrossRef]

177. Kawaguchi, K.; Sakaida, I.; Tsuchiya, M.; Omori, K.; Takami, T.; Okita, K. Pioglitazone prevents hepatic steatosis, fibrosis, and enzyme-altered lesions in rat liver cirrhosis induced by a choline-deficient l-amino acid-defined diet. Biochem. Biophys. Res. Commun. 2004, 315, 187-195. [CrossRef]

178. Leclercq, I.A.; Sempoux, C.; Stärkel, P.; Horsmans, Y. Limited therapeutic efficacy of pioglitazone on progression of hepatic fibrosis in rats. Gut 2006, 55, 1020-1029. [CrossRef]

179. Colca, J.R.; McDonald, W.G.; Cavey, G.S.; Cole, S.L.; Holewa, D.D.; Brightwell-Conrad, A.S.; Wolfe, C.L.; Wheeler, J.S.; Coulter, K.R.; Kilkuskie, P.M.; et al. Identification of a Mitochondrial Target of Thiazolidinedione Insulin Sensitizers (mTOT)—Relationship to Newly Identified Mitochondrial Pyruvate Carrier Proteins. PLoS ONE 2013, 8, e61551. [CrossRef]

180. McCommis, K.S.; Hodges, W.T.; Brunt, E.M.; Nalbantoglu, I.; McDonald, W.G.; Holley, C.; Fujiwara, H.; Schaffer, J.E.; Colca, J.; Finck, B.N. Targeting the mitochondrial pyruvate carrier attenuates fibrosis in a mouse model of nonalcoholic steatohepatitis. Hepatology 2017, 65, 1543-1556. [CrossRef]

181. Skat-Rørdam, J.; Ipsen, D.H.; Lykkesfeldt, J.; Tveden-Nyborg, P. A role of peroxisome proliferator-activated receptor $\gamma$ in non-alcoholic fatty liver disease. Basic Clin. Pharmacol. Toxicol. 2019, 124, 528-537. [CrossRef] [PubMed] 
182. Hattori, S.; Dhar, D.K.; Hara, N.; Tonomoto, Y.; Onoda, T.; Ono, T.; Yamanoi, A.; Tachibana, M.; Tsuchiya, M.; Nagasue, N. FR-167653, a selective p38 MAPK inhibitor, exerts salutary effect on liver cirrhosis through downregulation of Runx2. Lab. Investig. 2007, 87, 591-601. [CrossRef]

183. Cao, Z.; Sun, B.; Zhao, X.; Zhang, Y.; Gu, Q.; Liang, X.; Dong, X.; Zhao, N. The Expression and Functional Significance of Runx2 in Hepatocellular Carcinoma: Its Role in Vasculogenic Mimicry and Epithelial-Mesenchymal Transition. Int. J. Mol. Sci. 2017, 18, 500. [CrossRef] [PubMed]

184. Sahai, A.; Malladi, P.; Melin-Aldana, H.; Green, R.M.; Whitington, P.F. Upregulation of osteopontin expression is involved in the development of nonalcoholic steatohepatitis in a dietary murine model. Am. J. Physiol. Liver Physiol. 2004, 287, G264-G273. [CrossRef]

185. Kolodziejczyk, A.A.; Zheng, D.; Shibolet, O.; Elinav, E. The role of the microbiome in NAFLD and NASH. EMBO Mol. Med. 2018, 11, e9302. [CrossRef] [PubMed]

186. Bäckhed, F.; Ding, H.; Wang, T.; Hooper, L.V.; Koh, G.Y.; Nagy, A.; Semenkovich, C.F.; Gordon, J.I. The gut microbiota as an environmental factor that regulates fat storage. Proc. Natl. Acad. Sci. USA 2004, 101, 15718-15723. [CrossRef] [PubMed]

187. Zeng, H.; Liu, J.; Jackson, M.I.; Zhao, F.-Q.; Yan, L.; Combs, G.F. Fatty liver accompanies an increase in lactobacillus species in the hind gut of C57BL/6 mice fed a high-fat diet. J. Nutr. 2013, 143, 627-631. [CrossRef] [PubMed]

188. Wang, R.; Li, H.; Yang, X.; Xue, X.; Deng, L.; Shen, J.; Zhang, M.; Zhao, L.; Zhang, C. Genetically Obese Human Gut Microbiota Induces Liver Steatosis in Germ-Free Mice Fed on Normal Diet. Front. Microbiol. 2018, 9. [CrossRef]

189. Chiu, C.-C.; Ching, Y.-H.; Li, Y.-P.; Liu, J.-Y.; Huang, Y.-T.; Huang, Y.-W.; Yang, S.-S.; Huang, W.-C.; Chuang, H.-L. Nonalcoholic Fatty Liver Disease Is Exacerbated in High-Fat Diet-Fed Gnotobiotic Mice by Colonization with the Gut Microbiota from Patients with Nonalcoholic Steatohepatitis. Nutrients 2017, 9, 1220. [CrossRef]

190. Lambert, J.E.; Parnell, J.A.; Eksteen, B.; Raman, M.; Bomhof, M.R.; Rioux, K.P.; Madsen, K.L.; Reimer, R.A. Gut microbiota manipulation with prebiotics in patients with non-alcoholic fatty liver disease: A randomized controlled trial protocol. BMC Gastroenterol. 2015, 15, 169. [CrossRef]

191. Perumpail, B.J.; Li, A.A.; John, N.; Sallam, S.; Shah, N.D.; Kwong, W.; Cholankeril, G.; Kim, D.; Ahmed, A. The Therapeutic Implications of the Gut Microbiome and Probiotics in Patients with NAFLD. Diseases 2019, 7, 27. [CrossRef]

192. Cheng, Y.-W.; Phelps, E.; Ganapini, V.; Khan, N.; Ouyang, F.; Xu, H.; Khanna, S.; Tariq, R.; Friedman-Moraco, R.J.; Woodworth, M.H.; et al. Fecal microbiota transplantation for the treatment of recurrent and severe Clostridium difficileinfection in solid organ transplant recipients: A multicenter experience. Arab. Archaeol. Epigr. 2018, 19, 501-511. [CrossRef]

193. Aron-Wisnewsky, J.; Gaborit, B.; Dutour, A.; Clément, K. Gut microbiota and non-alcoholic fatty liver disease: New insights. Clin. Microbiol. Infect. 2013, 19, 338-348. [CrossRef] [PubMed]

194. Arab, J.P.; Karpen, S.J.; Dawson, P.A.; Arrese, M.; Trauner, M. Bile acids and nonalcoholic fatty liver disease: Molecular insights and therapeutic perspectives. Hepatology 2016, 65, 350-362. [CrossRef] [PubMed]

195. Cruz-Ramón, V.; Chinchilla-López, P.; Ramírez-Pérez, O.; Méndez-Sánchez, N. Bile Acids in Nonalcoholic Fatty Liver Disease: New Concepts and Therapeutic Advances. Ann. Hepatol. 2017, 16, S58-S67. [CrossRef]

196. Chiang, J.Y. Bile acid metabolism and signaling in liver disease and therapy. Liver Res. 2017, 1, 3-9. [CrossRef]

197. Leung, C.; Rivera, L.; Furness, J.B.; Angus, P.W. The role of the gut microbiota in NAFLD. Nat. Rev. Gastroenterol. Hepatol. 2016, 13, 412-425. [CrossRef]

198. Wang, L.; Wan, Y.-J.Y. The role of gut microbiota in liver disease development and treatment. Liver Res. 2019, 3, 3-18. [CrossRef]

199. Jones, B.V.; Begley, M.; Hill, C.; Gahan, C.G.; Marchesi, J.R. Functional and comparative metagenomic analysis of bile salt hydrolase activity in the human gut microbiome. Proc. Natl. Acad. Sci. USA 2008, 105, 13580-13585. [CrossRef]

200. Xie, C.; Jiang, C.; Shi, J.; Gao, X.; Sun, D.; Sun, L.; Wang, T.; Takahashi, S.; Anitha, M.; Krausz, K.W.; et al. An Intestinal Farnesoid X Receptor-Ceramide Signaling Axis Modulates Hepatic Gluconeogenesis in Mice. Diabetes 2016, 66, 613-626. [CrossRef] 
201. Jiang, C.; Xie, C.; Li, F.; Zhang, L.; Nichols, R.G.; Krausz, K.W.; Cai, J.; Qi, Y.; Fang, Z.-Z.; Takahashi, S.; et al. Intestinal farnesoid $X$ receptor signaling promotes nonalcoholic fatty liver disease. J. Clin. Investig. 2014, 125, 386-402. [CrossRef] [PubMed]

202. Gao, Z.; Yin, J.; Zhang, J.; Ward, R.E.; Martin, R.J.; Lefevre, M.; Cefalu, W.T.; Ye, J. Butyrate Improves Insulin Sensitivity and Increases Energy Expenditure in Mice. Diabetes 2009, 58, 1509-1517. [CrossRef] [PubMed]

203. Besten, G.D.; Van Eunen, K.; Groen, A.K.; Venema, K.; Reijngoud, D.-J.; Bakker, B.M. The role of short-chain fatty acids in the interplay between diet, gut microbiota, and host energy metabolism. J. Lipid Res. 2013, 54, 2325-2340. [CrossRef] [PubMed]

204. Liu, S.; Gallo, D.J.; Green, A.M.; Williams, D.L.; Gong, X.; Shapiro, R.A.; Gambotto, A.A.; Humphris-Narayanan, E.; Vodovotz, Y.; Billiar, T.R. Role of Toll-Like Receptors in Changes in Gene Expression and NF- $\mathrm{BB}$ Activation in Mouse Hepatocytes Stimulated with Lipopolysaccharide. Infect. Immun. 2002, 70, 3433-3442. [CrossRef] [PubMed]

205. Hoang, S.A.; Oseini, A.; Feaver, R.E.; Cole, B.K.; Asgharpour, A.; Vincent, R.; Siddiqui, M.S.; Lawson, M.J.; Day, N.; Taylor, J.; et al. Gene Expression Predicts Histological Severity and Reveals Distinct Molecular Profiles of Nonalcoholic Fatty Liver Disease. Sci. Rep. 2019, 9, 12541. [CrossRef] [PubMed]

206. Arendt, B.M.; Comelli, E.M.; Ma, D.W.; Lou, W.; Teterina, A.; Kim, T.; Fung, S.K.; Wong, D.K.; McGilvray, I.D.; Fischer, S.E.; et al. Altered hepatic gene expression in nonalcoholic fatty liver disease is associated with lower hepatic n-3 and n-6 polyunsaturated fatty acids. Hepatology 2015, 61, 1565-1578. [CrossRef]

207. Cichocki, J.A.; Furuya, S.; Konganti, K.; Luo, Y.-S.; McDonald, T.J.; Iwata, Y.; Chiu, W.A.; Threadgill, D.W.; Pogribny, I.P.; Rusyn, I. Impact of Nonalcoholic Fatty Liver Disease on Toxicokinetics of Tetrachloroethylene in Mice. J. Pharmacol. Exp. Ther. 2017, 361, 17-28. [CrossRef]

208. Maeso-Diaz, R.; Boyer-Diaz, Z.; Lozano, J.J.; Ortega-Ribera, M.; Peralta, C.; Bosch, J.; Gracia-Sancho, J. New rat model of advanced nash mimicking pathophysiological features and transcriptomic signature of the human disease. Cells 2019, 8, 1062. [CrossRef]

209. Qin, G.; Wang, G.Z.; Guo, D.D.; Bai, R.-X.; Wang, M.; Du, S.Y. Deletion of Smad4 reduces hepatic inflammation and fibrogenesis during nonalcoholic steatohepatitis progression. J. Dig. Dis. 2018, 19, 301-313. [CrossRef]

210. Valenti, L.; Mendoza, R.M.; Rametta, R.; Maggioni, M.; Kitajewski, C.; Shawber, C.J.; Pajvani, U.B. Hepatic notch signaling correlates with insulin resistance and nonalcoholic fatty liver disease. Diabetes 2013, 62, 4052-4062. [CrossRef]

211. Liang, N.; Damdimopoulos, A.; Goni, S.; Huang, Z.; Vedin, L.L.; Jakobsson, T.; Giudici, M.; Ahmed, O.; Pedrelli, M.; Barilla, S.; et al. Hepatocyte-specific loss of GPS2 in mice reduces non-alcoholic steatohepatitis via activation of PPAR $\alpha$. Nat. Commun. 2019, 10, 1684. [CrossRef] [PubMed]

212. Porteiro, B.; Fondevila, M.F.; Delgado, T.C.; Iglesias, C.; Imbernon, M.; Iruzubieta, P.; Crespo, J.; Zabala-Letona, A.; Ferno, J.; Gonzalez-Teran, B.; et al. Hepatic p63 regulates steatosis via IKK $\beta /$ ER stress. Nat. Commun. 2017, 8, 15111. [CrossRef] [PubMed]

213. Li, Z.; Yu, P.; Wu, J.; Tao, F.; Zhou, J. Transcriptional regulation of early growth response gene-1 (EGR1) is associated with progression of nonalcoholic fatty liver disease (NAFLD) in patients with insulin resistance. Med. Sci. Monit. 2019, 25, 2293-3004. [CrossRef] [PubMed]

214. Cheng, C.; Deng, X.; Xu, K. Increased expression of sterol regulatory element binding protein-2 alleviates autophagic dysfunction in NAFLD. Int. J. Mol. Med. 2018, 41, 1877-1886. [CrossRef]

215. Kabbani, M.; Michailidis, E.; Steensels, S.; Zou, C.H.; Zeck, B.; Inna, R.L.; Fulmer, C.G.; Quirk, C.; Ashbrook, A.W.; Belkaya, S.; et al. PNPLA3-148M Overexpression in primary human hepatocytes exacerbates steatosis in tissue culture and chimeric mouse models of NAFLD. Hepatology 2019, 70, 1325A-1326A.

(C) 2020 by the authors. Licensee MDPI, Basel, Switzerland. This article is an open access article distributed under the terms and conditions of the Creative Commons Attribution (CC BY) license (http://creativecommons.org/licenses/by/4.0/). 